San Jose State University

SJSU ScholarWorks

Doctoral Projects

Master's Theses and Graduate Research

Spring 5-2014

\title{
Impact of Cue-Based Feeding Protocol on Premature Infants' Outcomes and Hospital Length of Stay
}

Diana Michele Easley Cormier

California State University, Northern California Consortium Doctor of Nursing Practice

Follow this and additional works at: https://scholarworks.sjsu.edu/etd_doctoral

Part of the Maternal, Child Health and Neonatal Nursing Commons

\section{Recommended Citation}

Cormier, Diana Michele Easley, "Impact of Cue-Based Feeding Protocol on Premature Infants' Outcomes and Hospital Length of Stay" (2014). Doctoral Projects. 51.

DOI: https://doi.org/10.31979/etd.rfc4-mhaw

https://scholarworks.sjsu.edu/etd_doctoral/51

This Doctoral Project is brought to you for free and open access by the Master's Theses and Graduate Research at SJSU ScholarWorks. It has been accepted for inclusion in Doctoral Projects by an authorized administrator of SJSU ScholarWorks. For more information, please contact scholarworks@sjsu.edu. 


\title{
IMPACT OF CUE-BASED FEEDING PROTOCOL ON PREMATURE INFANTS' OUTCOMES AND HOSPITAL LENGTH OF STAY
}

\author{
by \\ Diana Michele Easley Cormier
}

\author{
A project \\ submitted in partial \\ fulfillment of the requirements for the degree of \\ Doctor of Nursing Practice (DNP) \\ in the California State University Northern Consortium DNP Program \\ California State University, Fresno and San Jose State University \\ May of 2014
}




\section{ABSTRACT \\ IMPACT OF CUE_BASED FEEDING PROTOCOL ON PREMATURE INFANTS' OUTCOMES AND HOSPITAL LENGTH OF STAY}

The project was an oral feeding practice change from traditional, gestational-age/volumedriven feeding progression to developmentally-based, infant-driven feeding progression. The infant-driven (cue-based) feeding protocol was implemented with goals to improve premature infants' feeding outcomes, and decreased the infant's length of hospitalization. The project was designed to implement a cue-based feeding protocol for oral feeding initiation and progression, within the neonatal intensive care unit (NICU) at Community Regional Medical Center (CRMC), and then retrospectively evaluate the impact of the cue-based feeding protocol on feeding outcomes. In order to realize full implementation of a NICU feeding practice change, multiple components, such as electronic charting, feeding policy, staff education and data reports, needed to be developed.

Multiple unit- and hospital-level barriers prevented timely project implementation. Given the DNP program time constraints for project implementation, and the complex nature of project review and approval by nursing leadership, final, post-protocol data collection and analysis could not be completed. Delays in project implementation did not allow for oral feeding outcome evaluation, as originally proposed, however, the project did produce valuable instruments for recording and measuring feeding outcomes in the future.

Future plans for project follow-up have been established by NICU nursing leadership. Data for 6-month and 1-year feeding outcomes will be collected and evaluated, with the intention to present results to: 1) CRMC corporate leadership, 2) CPQCC 1-year collaborative follow-up (June 2014); and 3) Central Valley Nursing Research Conference 2015. Keywords: neonatal, developmental-care, oral feeding, premature infant, cue-based 


\section{Acknowledgements}

This manuscript is dedicated to all of the individuals who have contributed to and participated in this project. Their assistance and support for the idea of this project has been paramount to making the completion of this manuscript a reality. The author wishes to express an indebted gratitude and appreciation to those colleagues who gave of their time and expertise in providing assistance in developing all of the components of this project, particularly Abby Van den Broeke, Neonatal Nurse Practitioner (NNP), and Brandy Snowden. The support of my project chair, Dr. Terea Giannetta, and committee members Dr. Krishna Rajani and Donna McCloudy, have been invaluable. Lastly, this is dedicated to those dearest to me: Burke Farrah, Stacie Szatmari, and my phenomenal family, particularly, the most special individual who has guided and encouraged me throughout all of my years of education, my mother Phyllis M. Cormier-Maloof. 


\section{APPROVED}

\section{For the Department of Nursing:}

We, the undersigned, certify that the doctor of nursing practice project of the following student meets the required standards of scholarship, format, and style of the university and the student's graduate degree program for the awarding of the doctor of nursing practice degree.

Diana Michele Easley Cormier

DNP Project Author
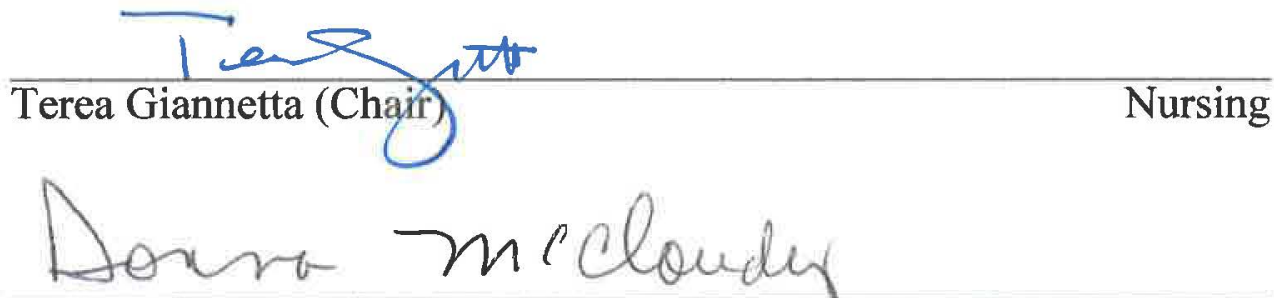

Donna MeGloudy Community Regional Medical Center

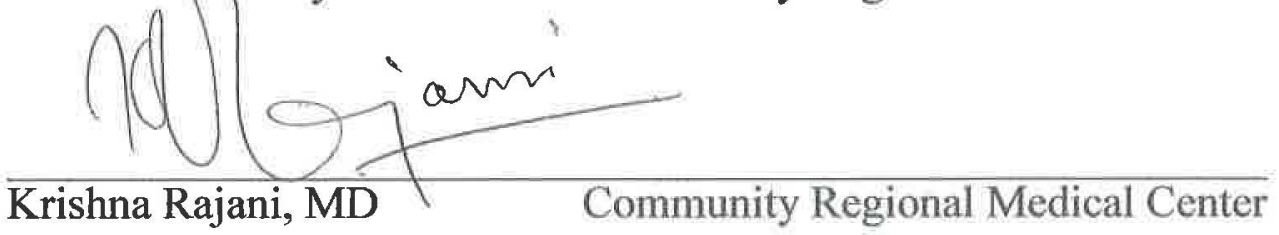




\section{AUTHORIZATION FOR REPRODUCTION OF DOCTORAL PROJECT}

I grant permission for the reproduction of this project in part or in its entirety without further authorization from me, on the condition that the person or agency requesting reproduction absorbs the cost and provides proper acknowledgment of authorship.

Permission to reproduce this project in part or in its entirety must be obtained from me.

Signature of DNP project author:

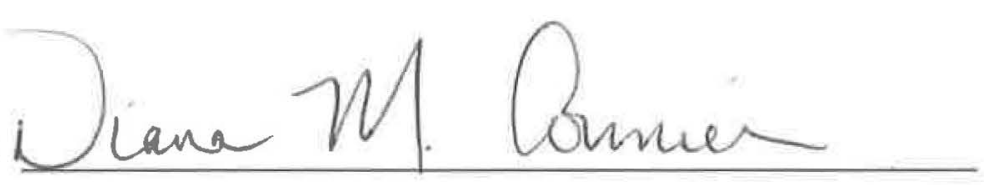




\section{Table of Contents}

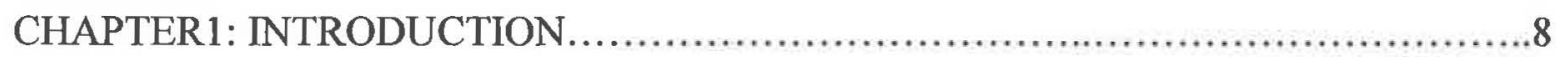

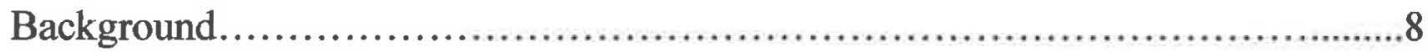

Problem Statement................................................................ 10

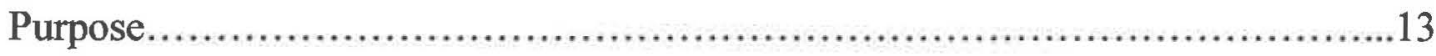

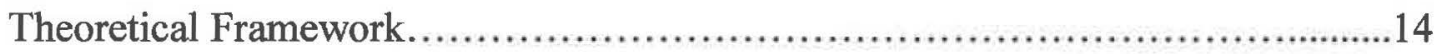

CHAPTER 2: REVIEW OF LITERATURE...........................................16

Synactive Theory of Development......................................................

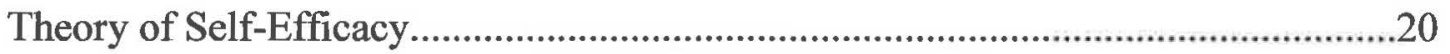

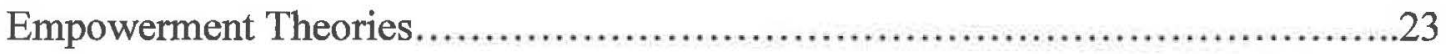

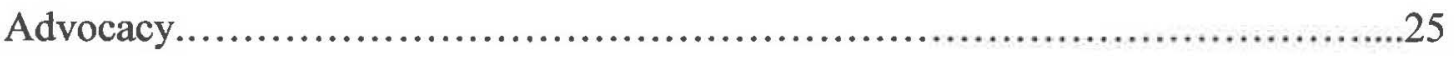

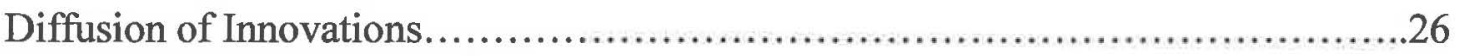

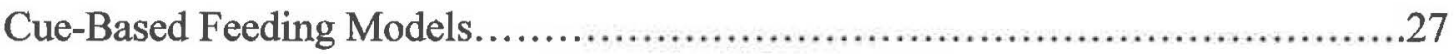

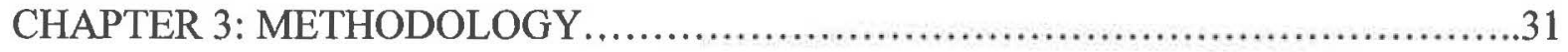

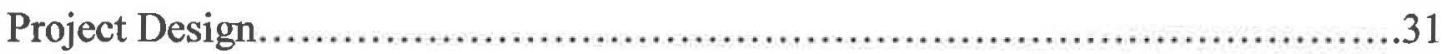

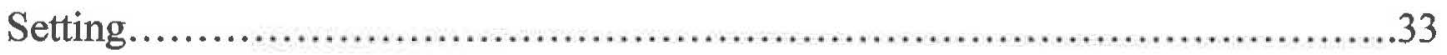

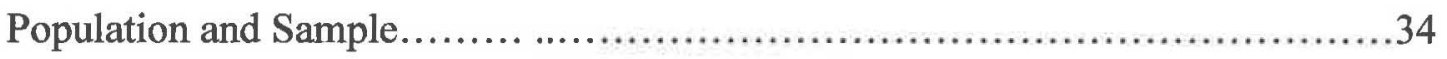

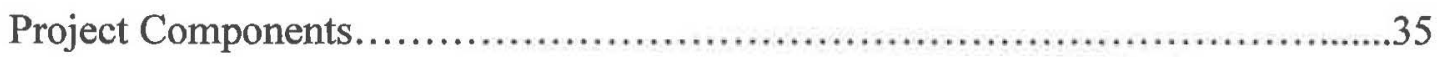

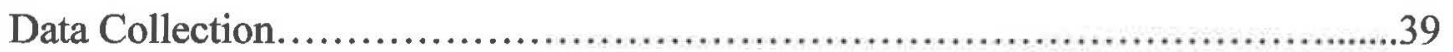

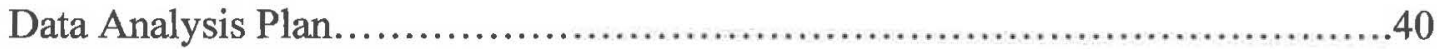

Ethical Consideration (Human Subject Protection).............................42

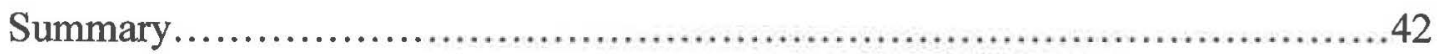

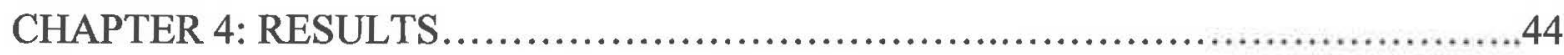

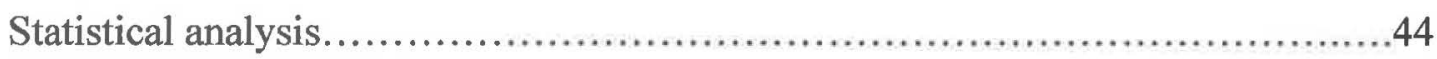

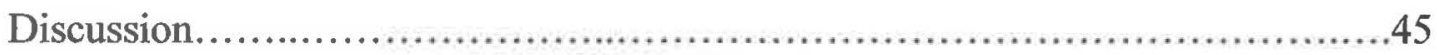

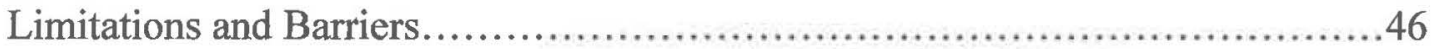

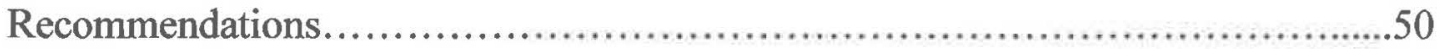


IMPACT OF CUE-BASED FEEDING PROTOCOL

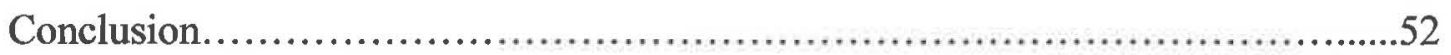

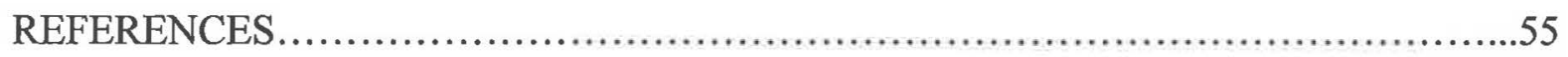

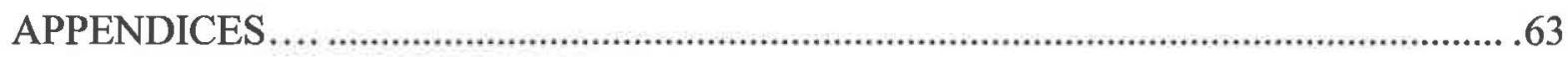

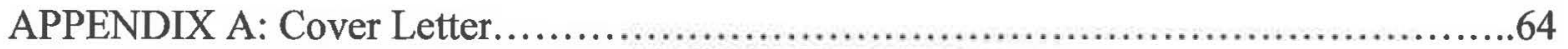

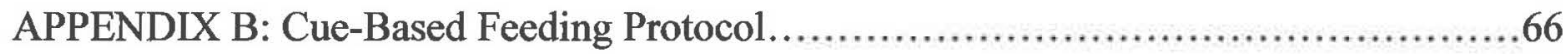

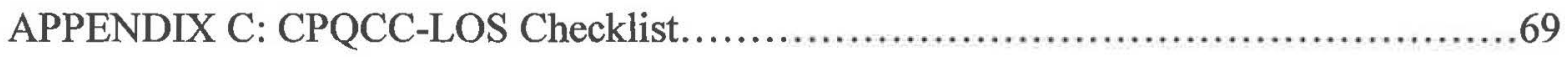

APPENDIX D: Cue-Based Feeding Data Collection Sheet...............................72

APPENDIX E: Cue-Based Feeding Electronic Charting (EPIC)..........................74

APPENDIX F: Existing NICU Data Reports.........................................78

APPENDIX G: Cue-Based Feeding Staff Education Course..............................81

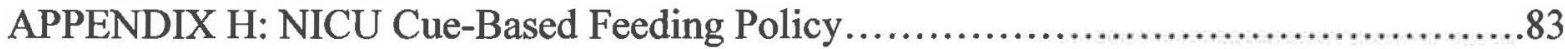


IMPACT OF CUE-BASED FEEDING PROTOCOL

\section{CHAPTER 1: INTRODUCTION}

\section{Background}

Since 1981 , more than 480,000 premature infants have been born annually in the United States (Hamilton, Martin, \& Sutton, 2004). Data culminated from the Centers for Disease Control (CDC), National Vital Statistics Reports, (2004) has shown that, in addition to the $27 \%$ overall rise in premature births, of the total annual number of premature births during the past three decades, over 40,000 infants are born extremely premature (EP), at less than 28 weeks in gestation. Although advances in technology have allowed greater numbers of premature infants to survive, morbidity has remained high. High morbidity related to prematurity has imposed great emotional and financial burdens on families, society, and the healthcare system (Schrader, Heverly, O’Brien, \& Goodman, 1997).

The premature infant's natural rate and process of development is altered by early birth, when they are separated from the protection of the uterus and forced to interact with a foreign environment. They are ill-equipped to handle their new environment due to their small size, immature body systems, lack of immune protection, and inability to physiologically self-regulate (Als \& Brazelton, 1981). The technology and professionals within the neonatal intensive care unit (NICU) become surrogates governing the early infant's survival. Premature infants are directly impacted by the caregiver's ability to adequately: 1) manage the safety and balance of their external environment; 2) assess and maintain their physiological stability; and 3) assess and anticipate growth and development needs.

Despite healthcare professionals' best efforts to protect premature infants from experiencing adverse effects related to premature birth and/or extended hospitalization, 


\section{IMPACT OF CUE-BASED FEEDING PROTOCOL}

longitudinal studies examining short and long-term complications have shown that, both low birth weight (LBW), and very-low birth weight (VLBW) premature infants, experience a diversity of adverse, physical, cognitive, and behavioral problems, that can persist well into the school-age and adolescent years (Bhutta, Cleves, Casey, Cradock, \& Anand, 2002; McGrath \& Sullivan, 2002). So, in addition to their initial, extensive hospitalization after birth, premature infants often grow up with physical and/or emotional/behavioral problems that require increased medical utilization post discharge.

Research analysis of common morbidities among premature infants, has shown, that pulmonary, neurodevelopmental, and gastrointestinal disease and dysfunction are major issues of concern for short-term and long-term disability (Bregman, 1998). These morbidities also represent delayed or failed achievement of major developmental milestones for the premature infant: 1) acquisition of breathing independent of respiratory support; 2) successful maturation and coordination of the autonomic, motor, state-organizational, and self-regulatory subsystems of the central nervous system; and 3) achieving feeding competence (Bregman, 1998).

While all aspects of growth and maturation are important, the final developmental milestone that must be achieved by premature infants, and has frequently caused a delay in hospital discharge, is the acquisition of oral feeding. Multiple studies have shown that, oral feeding is the most complex neonatal behavior requiring the physiological coordination of cardiorespiratory, gastrointestinal, and neurological systems, and the motor coordination of sucking, swallowing and breathing (Bertoncelli, et al, 2012). In a retrospective analysis of feeding abilities, Thoyre (2006), found that, EP infants are at highest risk for short and long-term feeding-related impairments, and particularly struggle with, acquiring oral feeding prior to going home. Due to the complexity of oral feeding skills, an infant's inability to wean from tube 


\section{IMPACT OF CUE-BASED FEEDING PROTOCOL}

feeding has often led to delayed hospital discharge and mother-infant reunion, and thereby, increased medical cost and maternal stress (Lau \& Hurst, 1999). Oral feeding is a skill that is automatically activated in the full-term infant, however, in the premature infant, oral feeding skills must be learned, and require that the caregiver work with the infant to develop effective feeding abilities (National Association of Neonatal Nurses [NANN], 2013; Shaker, 2012).

\section{Statement of the problem}

Caregivers face two dilemmas when addressing oral feeding difficulties: 1) infant inability to complete their feedings safely due to fatigue or physiological instability, and 2) achieving an appropriate rate of advancement to independent oral feeding (Crowe, Chang, \& Wallace, 2012; Lau \& Smith, 2011). Since persistent feeding problems can have significant consequences for infants and their families, the development of safe and effective oral feeding skills, must be a major clinical focus, and nursing care goal, during the final weeks of hospitalization (Shaker, 2012; Thoyre, 2006).

Assessment of the premature infants' oral feeding skills, and determination of appropriate feeding progression, has been difficult due to the lack of well-defined outcomes among neonatal clinicians, and the tendency of clinicians, to rely on volume consumption as the benchmark for successful oral feeding acquisition (Bregman, 1998; Crowe, Change, \& Wallace, 2012). The infant's ability to feed well is closely related to the caregiver's ability to understand and respond the infant's physiology and behavioral communication (Shaker, 2012). The premature infant's experience of feeding is strongly influenced by the actions of caregivers, which either support the infant's individual manner and pace of acquiring feeding skills, or hamper the infant's development of feeding skills (Shaker, 2012; Thoyre, Shaker, \& Pridham, 2005). Thus, depending on the perspective of the professional caregiver, the goal of feeding may be to 
facilitate a positive learning opportunity, or simply get the infant "to empty the bottle" (Shaker, 2013; p. 405). Studies within the last 5 years have clearly shown that, professional caregivers, particularly NICU nurses, play a critical role in directing the feeding progression and outcomes of premature infants (NANN, 2013; Shaker, 2012).

The American Academy of Pediatrics (AAP) (2008), issued a position statement that made the attainment of independent oral feeding one of the critical criteria for hospital discharge of preterm infants. This statement not only reflected nearly a decade of increased research emphasis on feeding outcomes, and feeding-related morbidities, but also forced practitioners to re-examine their feeding practices, so that premature infants could successfully accomplish oral feedings prior to discharge (Shaker, 2012; Thoyre, 2006). Extensive literature review has revealed that neonatal clinical practice has progressively moved toward developmentally based care (Coughlin, Gibbins, \& Hoath, 2009). For oral feeding, practitioners have been moving away from feeding schedules based primarily on gestational age criteria, or volume-matrices, and adopting feeding protocols that are based on physiologic (developmental) maturity, known as, feeding readiness (Crowe, Change, \& Wallace, 2012; Pickler, 2004; Shaker, 2013). Thus, feeding practices are increasingly infant-driven, where infants indicate through specific types of behavior, when they are ready to initiate, and progress through, oral feedings (Pickler, 2004). This type of feeding practice is known as cue-based feeding.

The trend toward developmentally supportive care, and increased focus on improving neonatal outcomes, has been reflected in the increase in state and national quality care initiatives, most recently, the collaborative, promulgated by the California Neonatal Quality Improvement (NQI) which commenced on June 7, 2013. The California Perinatal Quality Care Collaborative (CPQCC) "Optimizing the Length of Separation (LOS)", administrated by the California 
Children's Services (CCS) mandated NICU practice changes statewide. Participating NICUs statewide were charged with establishing goals and objectives to improve the quality of care and safety for their neonatal patients. Over the first 12 months (June, 2013 to June, 2014), participating NICUs would be required to identify and then implement best practices in 3 care areas: 1) feeding, 2) discharge planning, and 3) cardiopulmonary stability (defined as clinically significant cardiopulmonary events [CSCE]). With regards to feeding, the specific objective mandated by the CPQCC-LOS was to standardize nutritional best practices based on physiologic maturity rather than gestational age criteria (CPQCC/CCS, 2013). Essential practice components must include: (a) standardized enteral feeding initiation, and advancement, for optimal growth; and (b) standardized transition to oral feeding, based on physiologic maturity, not gestational age, nor weight (ideally based upon feeding readiness scores) (CPQCC/CCS, 2013).

The project presented in the remainder of this manuscript is due, in part, to satisfy requirements for the completion of the doctor of nursing practice (DNP) degree, and in part, to fulfill mandates from the California Perinatal Quality Care Collaborative (CPQCC). Initially, the project was developed as a retrospective, observational, research study to evaluate the impact of a developmentally cue-based feeding protocol on feeding outcomes in a select group of infants. However, after presentation of the study proposal to the medical practitioners, and NICU management, during the months of May and June, 2013, a decision was made by the NICU leadership to be congruent with the upcoming CPQCC collaborative requirements, and adopt the cue-based feeding protocol (study) as the standard of practice. The focus then shifted from implementing a study performed on a selected group of patients, to a project evaluating the feeding outcomes of all patients in the NICU following a feeding practice change. The project 


\section{IMPACT OF CUE-BASED FEEDING PROTOCOL}

was then designed to evaluate the implementation process for the feeding practice change, as well as, the impact of that practice change on neonatal feeding outcomes.

\section{Project purpose}

The purpose of the project was to implement a cue-based oral feeding protocol within the NICU at Community Regional Medical Center (CRMC), and evaluate its impact on feeding outcomes. Following implementation of the cue-based feeding protocol, a retrospective comparison of feeding outcomes from gestational- age/ volume-driven feeding progression (preprotocol practice), to outcomes from an infant-driven, cue-based feeding protocol (new practice), was to be completed. Literature has shown that cue-based feeding protocols have improved premature infants' feeding outcomes, primarily by decreasing the stress of oral feeding and decreasing the amount of time needed for oral feeding acquisition (Lau \& Smith, 2011; Pickler, 2004). Decreasing the time needed to acquire oral feeding competency, decreases length of hospital stay, and the length of mother-infant separation (California Perinatal Quality Care Collaborative, 2013). The project then, was designed to include both protocol implementation and evaluation, in order to determine, whether or not, adopting a developmentally supportive method for feeding premature infants would lead to improved feeding outcomes as discussed in the literature. The project was conducted to meet the following objectives:

1. To facilitate the transition of oral feeding practices in the NICU from traditional gestational-age criteria or, volume-based feeding progression, to infant-driven, cuebased feeding.

2. To improve neonatal feeding outcomes and decrease medical cost/infant length of hospitalization (length of separation) through the use of a cue-based oral feeding protocol. 
IMPACT OF CUE-BASED FEEDING PROTOCOL

3. To improve the assessment and documentation of feeding readiness, and feeding outcomes, as a result of building the cue-based feeding protocol into the electronic health record (EPIC) charting system.

4. To comply with California Perinatal Quality Care Collaborative (CPQCC) "Optimizing the Length of Separation (LOS)" mandate for improving quality of care and patient safety, by developing a standardized, nutritional best-practice oral feeding program based on physiological maturity.

5. To meet the requirements for implementing nursing-driven practice changes that improve patient outcomes, as specified by the Northern California Doctorate of Nursing Practice (NORCAL DNP) Program, nursing essentials.

\section{Theoretical Framework}

Multiple theories framed diverse aspects of the project: 1) developmental needs of premature infants, 2) parental needs for building self-confidence in infant care, 3) enhancing nurse-performance outcomes, 4) increasing the nursing advocacy role, and 5) facilitating practice change through a diversified educational approach. The integration of multiple theories into the project frame reflects the historical trends of nursing care where knowledge from multiple disciplines have been combined to optimize patient care and outcomes. The theories incorporated into the project are captured in the following figure (see Figure 1).

Figure 1: Project Theoretical Framework 


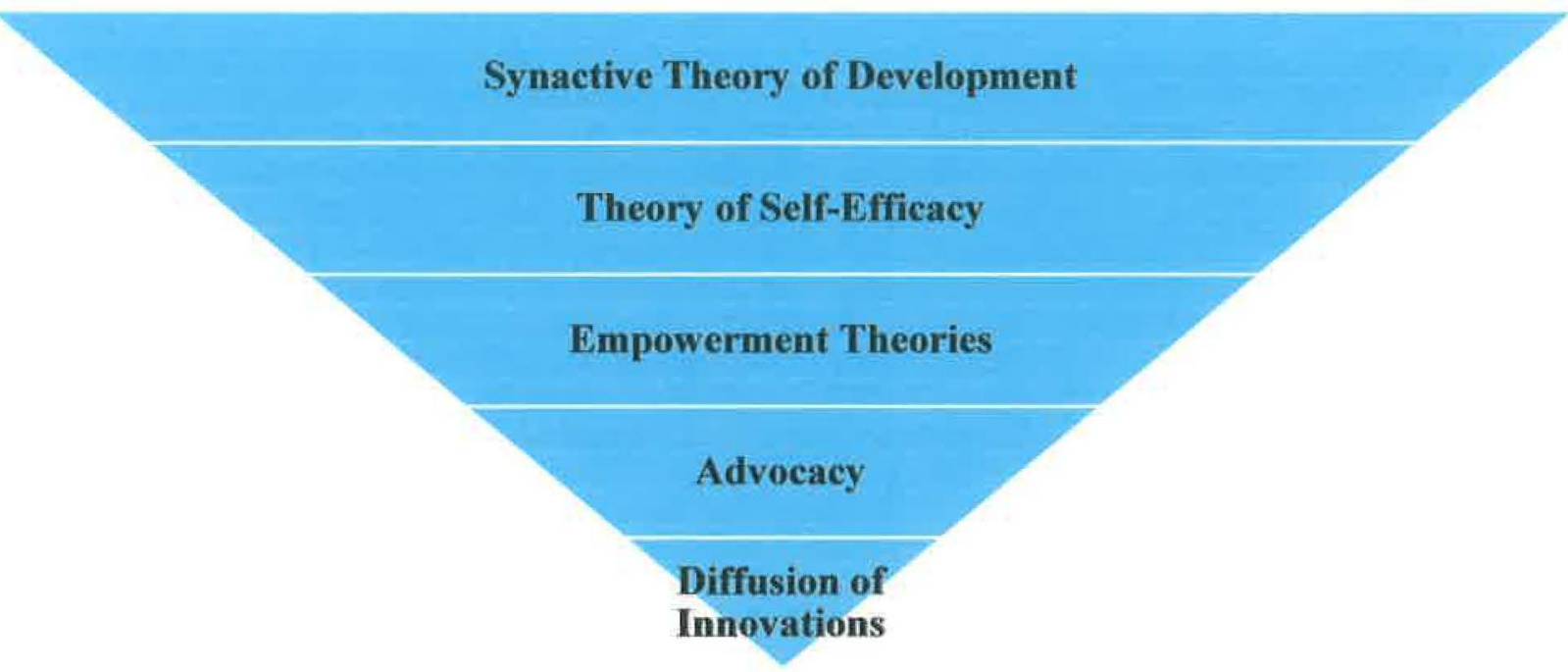

Figure 1. As the prevailing foundational, developmental theory in neonatal research and care, the Synactive Theory of Development, serves as the framework for the cue-based feeding protocol. Frequently used in studies examining the impact of extensive NICU hospitalization on parents and family support systems, the Theory of Self-efficacy is emphasized in the family-centered care practices in the CRMC NICU. Empowerment theories commonly frame nursing leadership studies and are frequently associated with enhanced nurse, and nurse-leader performance, and improved patient outcomes. The cue-based feeding protocol represents nurse-driven practice change and engages nurses as stakeholders, increasing their empowerment. Advocacy, one of the foundational principles of nursing practice, and a critical component in nursing leadership, is enhanced by a cuebased feeding protocol. Diffusion of Innovations is one of the most prominent theories in behavior change models, because it promotes active transfer of knowledge using multiple modalities for delivering education. Behavior change facilitated by information exchange and adoption of action results in practice change. 


\section{CHAPTER 2: LITERATURE REVIEW}

So that, the context and purpose of the project was clear, the literature reviewed, presented discussion, and analysis of developmental and family-centered care as they related to supporting the premature infant's acquisition of oral feeding. Empowerment theories that applied to nurse and parent role functions in oral feeding were reviewed. For this developmentally supportive feeding program, multiple intersecting theories: 1) the synactive theory of development (Als, 1982), 2) the theory of self-efficacy (Bandura, 1977), 3) empowerment theory (Kanter, 1993), 4) advocacy (Smith, 2004), and 5) the diffusion of innovations theory (Rogers, 1983), were utilized in the conceptual framework for the project that proposed to develop and implement a cue-based feeding protocol, for premature infants in the neonatal intensive care unit (NICU) at Community Regional Medical Center (CRMC). Finally, cue-based feeding protocols were reviewed and evaluated as foundational models for the development of the overall feeding protocol that would be utilized by nurses and parents in the NICU at CRMC.

\section{Synactive Theory of Development}

The majority of the literature reviewed was devoted to the synactive theory of development (Als, 1982). This theory has been the foundational theory in developmental care, family centered care, and cue-based feeding studies for over 30 years, and provided the conceptual foundation for project. Derived from extensive neurobehavioral and neurophysiological studies by Dr. Heidelise Als (1982), the synactive theory posits that premature infants interact with, and adapt to, their environment through the integrated activity of four neurological subsystems; 1) autonomic; 2) motor; 3) behavioral; and 4) attentional. Development proceeds through the continuous balancing between, approach to, and avoidance 
of, environmental stimulation. Neurobehavioral and neurophysiological maturity results from continuous intra-organism subsystem interaction and differentiation in response to environmental stimulus (Als \& Brazelton, 1981). Throughout development, the overall maturation and mutual interplay of physiological and behavioral subsystems, is governed by a process known as selfregulation, or self-stabilization (Als \& Brazelton, 1981).

As a core concept of the synactive theory, self-regulation describes the infant's process of adjusting to environmental stimulation. In other words, self-regulation describes the infant's ability to stabilize to environmental input. As infant development proceeds through the continuous adjustment to environmental stimulation, developmental maturity is marked by the infant's increased ability to self-stabilize (adjust) to that stimulation, as manifested by decreased signs of stimulation-related stress.

The central hypothesis of the synactive theory is that environmental input may lead to an altered pathway of development, due to unexpected and overwhelming sensory experience, which in turn may lead to deviant developmental functioning (Als, 1982). The synactive theory allows for clinical assessment of the immature nervous system's readiness for sensory input, and subsequent evaluation of behavioral efforts, that signal developmental organization/integration (adjustment) verses disorganization (stress) (Als, 1982). The synactive theory then, also advocates for the modification of environmental input, and caregiving techniques, in keeping with the infant's current level of developmental organization, or ability to self-regulate. In other words, caregivers directly impact the path of the premature infant's development through their caregiving practices, by either supporting or hindering the infant's ability to self-stabilize. In an analytical review of a, multi-center randomized controlled trial (RCT) study of developmentally supportive care, known as the Newborn Individualized Developmental Care and Assessment 
Program (NIDCAP), Westrup (2007), found that, care practices founded on promoting a premature infant's physiologic self-regulation, facilitated developmental progress and competence, as evidenced by decreased stress responses during care giving activities.

Self-regulation is the basis for the concept of contingent care-giving, where caregiving plans are individualized, and hinge upon the infant's readiness for stimulation (Pickler, 2004). Caregiving is directed toward the infant's demonstration of behavioral organization, known as behavioral cues. Following a comprehensive review of literature examining the relationships between feeding readiness, experience, and outcomes, Pickler (2004), linked infant selfregulation and feeding performance, by showing that, infant feeding performance is predicted by behavioral readiness indicators. Thus, self-regulation and contingent caregiving have been established as core concepts in developmentally-based feeding protocols (Newland, L'Huillier, \& Petrey, 2013; Thoyre, Shaker \& Pridham, 2005). Both prospective and retrospective feeding studies incorporating synactive theory, have shown that, breast/bottle feeding is particularly amenable to contingent caregiving, because the infant will demonstrate, "demand" or "selfregulatory" behaviors as indicators of feeding readiness (McCain \& Gartside, 2002, p. 188; Pridham et al., 2001). The infant's autonomic, motor, and behavioral activity is driven by the infant's need to self-regulate and adjust to their environment. Achieving feeding competence takes time, and requires that the infant make ongoing adjustments to changing environmental stimuli, to successfully adapt to the stimulation of eating.

Therefore, according to synactive theory constructs, feeding readiness is based on: 1) neurologic maturation as evidenced in behavioral response to environmental stimuli; 2) physiological stability in relation to the severity of their illness; 3) motor integration through suck-swallow-breathe coordination; and 4) overall pre-feeding autonomic, motor and behavioral 
IMPACT OF CUE-BASED FEEDING PROTOCOL

state organization (McCain \& Gartside, 2002; Pickler, 2004). The synactive theory suggests that caregivers can guide preterm infants toward meeting self-regulatory goals, by providing care contingent upon the infant's behaviors (Pickler, 2004).

The precursor to the infant's organization of behavioral subsystems, is the maturecoordination of the infant's autonomic subsystem, involving the organization of heart, and respiratory, rate, and rhythm (Bertoncelli et al, 2012). The infant must gain control over autonomic functioning before mechanical functioning, since the ability to achieve and maintain control in other areas depends upon the smooth, reliable function of autonomic mechanisms (Pickler, 2004; Shaker, 2009). Known as competence, the degree of smoothness in coordination of autonomic functions, reflects the infant's self-regulation abilities, and is communicated through the infant's approach to, or avoidance of stimulation (Premji, McNeil, \& Scotland, 2004). Bottle or breast feeding stresses the fragile organization of the preterm infant's autonomic subsystem by challenging the heart and respiratory functions. Infants with poor organization of autonomic subsystems have difficulty bottle feeding and will display avoidance cues (stress) when feeding is offered (Pickler, 2004; Premji, McNeil, \& Scotland, 2004). Thus, successful oral feeding, is feeding that does not lead to increased work of breathing, oxygen desaturation, and/or bradycardia. Therefore, feeding schedules that rely upon the infant's behavioral readiness to eat would be less stressful, as the infant would have gained cardiorespiratory control prior to signaling a need to eat.

Finally, the mechanical complexity of bottle feeding requires that the infant organize a pattern of sucking, swallowing and breathing. The coordinated suck-swallow-breathe sequence allows the infant to draw milk into the mouth and stimulate swallowing without an adverse disruption of breathing (Averdson et al, 2010). The mechanical action of feeding is 


\section{IMPACT OF CUE-BASED FEEDING PROTOCOL}

synchronized with the autonomic function of breathing. According to synactive theory, maturation underpins organization. As one developmental event, such as breathing is achieved, the infant moves on toward achieving more complex tasks, such as eating (Premji, McNeil, \& Scotland, 2004) This was demonstrated in a retrospective review of feeding studies, where researchers found that the ability of the infant to achieve coordinated suck-swallow-breath action, while maintaining autonomic, motor, and behavioral control, not only indicated a readiness to feed, but also acted as a predictor of successful outcomes (Pickler, Frankel, Walsh, \& Thompson, 1996). Developmental maturity then, hallmarks a degree physiological selfregulation that would allow an infant to safely eat. Again, as infants mature, they will communicate self-regulation and coordination of functions through approach behavioral cues that signal a readiness for interaction (Pickler, 2004; Premji, McNeil, \& Scotland, 2004).

\section{Theory of Self-Efficacy}

Self-efficacy theory originated from Bandura's (1977) social cognitive theory, and relates to the person's perception of their ability to reach a goal. Self-efficacy is an important concept in positive psychology, for it is an individual's expectation that they can master a situation, and produce a positive outcome (Bandura, 1982). Self-efficacy theory has not only been frequently utilized in studies examining the impact of neonatal hospitalization, on parental stress and coping mechanisms, but, has increasingly appeared in studies evaluating the importance of parent-infant social interaction during feedings to improve infant feeding outcomes (Premji, McNeil, \& Scotland, 2004; Shaker, 2013).

Parents of premature infants are at high risk for adverse effects. Parents of premature infants experience high stress levels, feelings of helplessness, and often lack adequate knowledge on how to interact with their premature baby, during its hospitalization in the neonatal intensive 


\section{IMPACT OF CUE-BASED FEEDING PROTOCOL}

care unit (NICU) (Melnyk et al, 2006). As feelings of inadequacy and apprehension build, parents frequently develop misperceptions of their infants, and have difficulty interacting with them in a developmentally sensitive manner (Miles, \& D'Auria, 1994). Referred to in the literature as negative parent-infant interaction trajectories, the alienation of parents from their infants have often led to adverse parent outcomes after hospitalization, such as depression, anxiety disorders, and dysfunctional parenting patterns (Miles, Holditch-Davis, Burchinal, \& Nelson, 1999; Melnyk et al, 2006). Thus self-efficacy theory is being increasingly used in NICU studies examining the impact of early intervention programs to reduce parental stress and improve parental confidence in caregiving abilities (Lee \& Weiss, 2009; Melnyk et al, 2006).

Self-efficacy theory was employed in the project through nurse role-modeling of developmentally supportive care, and instructing parents in cue-based feeding techniques. As parents participated in care and understood the importance of recognizing developmental cues for feeding, they displayed more enthusiasm when feeding their infants. As parents gained increased confidence in feeding, apprehension dissipated. The active transfer of knowledge and techniques, that occurred among nurses, during the implementation of cue-based feeding protocol, also occurred between nurses and parents. Family-centered, developmentally supportive care, was promoted by nurse-parent teaching, and noticeably improved parental confidence, and reduced parental stress, as evidenced by parents smiling at the bedside during feedings. In a large, multi-center, randomized, controlled trial of an educational-behavioral intervention program, focused on creating opportunities for parent empowerment (COPE), parents, who completed activities that promoted positive, developmentally sensitive interaction with their infants, experienced less anxiety, stress and depression, and more confidence (selfefficacy) in the care of their infant (Melnyk et al, 2006). These positive outcomes lasted well 


\section{IMPACT OF CUE-BASED FEEDING PROTOCOL}

after the infant was discharged home. Though this project focused on one aspect of developmental care, the opportunities for parental empowerment (self-efficacy) were created during infant feeding.

At the $6^{\text {th }}$ International Conference on Pervasive Computing Technologies for Healthcare (2012), researchers used Bandura's (1977) self-efficacy theory as the framework for developing technology strategies that aim to increase parenting confidence (Lee, Garfield, \& Kim, 2012). Self-efficacy theory and its role in interventions for parental support, was applied to the National Institute of Health (NIH)-funded research project, NICU-2-HOME. In the NICU-2-HOME project, Lee, Garfield and Kim (2012) found that interventions based upon self-efficacy theory led to increased parental awareness and self-confidence in their caring abilities, as well as, provided researchers with systematic guidance to design technologies to promote self-efficacy. During the project, as nurses instructed parents on how to recognize their infant's developmental cues for feeding readiness, they systematically guided parents toward achieving safe, enjoyable feeding events that facilitated parental self-efficacy.

Finally, the multi-disciplinary, systematic review of evidence that led to the creation of the Calgary Health Region Neonatal Oral Feeding Protocol (RNOFP) posited that an important relationship between the quality of the infant-caregiver interaction and the quality of the infant's feeding event existed (Premji, McNeil, \& Scotland, 2004). In the development of their oral feeding protocol, RNOFP researchers showed that by facilitating an active social interaction between parents and infants, positive feeding experiences increased (Premji, McNeil, \& Scotland, 2004). Recognizing that nurses have a profound impact on the nature of parent-infant feeding interactions, the RNOFP was designed to promote positive nurse- and parent-infant feeding interactions, where nurses would role-model positive feeding interactions and parents 
IMPACT OF CUE-BASED FEEDING PROTOCOL

would demonstrate. The promotion of parental self-efficacy then not only led to improved parental feeding skills, but improved feeding outcomes in the infants, as evidenced by improved sucking patterns, increased volume transfer and decreased stress during feeding (Premji, McNeil, \& Scotland, 2004).

\section{Empowerment theories}

Nurses have been natural front-line leaders, with the ability to affect the beliefs and attitudes of those around them, namely their co-workers, and visiting parents/family members. Education and role-modeling are the principle ways that nurses have empowered patients. In the NICU, nurses have used those same techniques to empower parents of premature infants. According to empowerment theories utilized in both, nursing leadership and business models, nurses themselves, have been empowered not only by taking more responsibility for their own practice decisions, but also, and in taking more ownership of practice changes within a unit (Marquis \& Huston, 2009).

This project promoted nurse-empowerment by emphasizing the concept of nurse-driven practice change, which caused the NICU nurses to adopt an increased role as stakeholders in the project. As interest in project's development and success increased, first among nurses, and then from nurses to parents, empowerment transferred through the NICU. Empowerment theories (Kanter, 1993, and Speitzer, 1995) have been associated with enhanced nurse and nurse leader performance and outcomes. Empowerment can be promoted on two fronts: 1) structural/organizational and 2) psychological (Macphee, Skelton-Green, Bouthillette, \& Suryaprakash, 2011). 
IMPACT OF CUE-BASED FEEDING PROTOCOL

Structural empowerment, an organizational theory based on Kanter's (1993) work, posits the importance of access to organizational empowerment structures that provide advancement opportunities, and access to information, support, and resources. One of the key types of access to empowerment structures is through peer networks (Laschinger, Finegan, \& Wilk, 2009). The Developmental Care Committee (DCC) in the NICU at CRMC is a peer network that was instrumental in the development and implementation of the cue-based feeding project. Made up of multiple disciplines (nursing, respiratory therapy, speech and physical therapy), the DCC members actively assisted in obtaining cue-based feeding research and disseminating information to the NICU staff. Committee members were committed to supporting the development of project components, such as staff education and policy drafting. Power sharing discussed by Yukl (2006), occurred during committee meetings, through the exchange of ideas and participatory decision-making. The power sharing process was important during project development and implementation. As staff members became more invested in the project's completion, and the reality of a true nurse-driven change in practice emerged, nurses increasingly volunteered to promote the project.

Psychological empowerment is regarded as an intrinsic motivational construct, and reflects the personal convictions employees have about their roles and responsibilities in an organization (Speitzer, 1995). Psychological empowerment is important for both NICU nurses and parents of premature infants. As nurses and parents derive more meaning, competence, selfdetermination, and impact from their roles and responsibilities, they will have increased psychological empowerment (Spreitzer, 1995). Self-efficacy is an important concept in positive psychology, for, it is an individual's expectation that they can master a situation, and produce a positive outcome (Bandura, 1982). Self-efficacy, and therefore psychological empowerment, 


\section{IMPACT OF CUE-BASED FEEDING PROTOCOL}

among nurses and parents was promoted through a phased, educational, roll-out process of the project. As nurses mastered the information and techniques related to cue-based feeding, they transferred that mastery to the parents. Increased nursing staff involvement with the project produced increased role identification with the project and promoted positive beliefs toward the project. Psychological empowerment became more evident as staff anticipated the project's completion and discussed how the practice change would benefit the NICU.

\section{Advocacy}

A critical leadership role in meeting and overcoming challenges to change is advocacy. Nurses and nursing leaders act as advocates by either helping others make informed decisions, by acting as intermediaries in the environment, or by directly intervening on the behalf of others (Marquis \& Huston, 2009). One of project's key purposes was to provide a safe, individualized feeding program that advocated infant development. The cue-based feeding protocol provided by the project, allowed for advocacy on multiple levels: 1) allowing nurses to intervene on the behalf of premature infants by feeding them in a safe, developmentally supportive manner, 2) allowing nurses to act as intermediaries within the NICU through their communication with providers, parents, and administration, and 3) helping parents build their caregiving skills and make informed decision about the care their infant is receiving. By creating a climate where advocacy was valued, the project promoted Smith's (2004) definition of patient advocacy through the trickle-down effect of building empowerment from: 1) nursing leadership to bedside nurses, and 2) bedside nurses to parents and their infants.

As stated previously, parents of premature infants are vulnerable to high stress levels, and feelings of helplessness and inadequacy (Melnyk et al, 2006). As nurses advocate for parents and their infants, parents feel more important as individuals, and begin to believe more in their 
role as parents. Advocacy then, precedes self-efficacy, where nurses advocate on behalf of the parents' needs to feel secure and confident as caregivers. Advocacy and self-efficacy were facilitated similarly through nurse role-modeling of developmentally supportive care, and teaching parents cue-based feeding techniques. As parental competence and confidence increased, fear, doubt and apprehension decreased (Melnyk et al, 2006). In the process of advocating for the individual needs of infants and their parents, NICU nurses advocated for the overall benefits of family-centered care through the promotion of increased parental participation in a developmentally supported feeding program. Literature has increasingly advocated for parental involvement in oral feeding by recognizing the significant parental contribution toward facilitating infant engagement during bottle feeding and improving infant oral feeding acquisition (Thoyre \& Brown, 2004).

\section{Diffusion of Innovations}

The concepts promoting feeding practice changes through the use of an evidenced-based protocol can be found in the diffusion of innovations theory. The diffusion of innovations theory, prevalent in public health-behavior models, describes an active approach for knowledge transfer from the resource system to the user system (Orlandi, Landers, Weston, \& Haley, 1990). Rogers (1983) defined innovation as the new idea, practice, or object that is adopted by an individual or group, through the systematic use of various forms of media and communication channels. Rogers (1983) proposed that new program or practice acquisition (innovation) occurred through the process of: 1) information dissemination through effective communication channels; 2) adoption of the program by the target users; 3 ) implementation of the program and promotion of self-efficacy of the target users; and 4) maintenance, or continued use of the innovation in practice (Oldenburg, Hardcastle, \& Kok, 1997). Optimal diffusion of an 
IMPACT OF CUE-BASED FEEDING PROTOCOL

innovation should involve a close collaborative partnership between those promoting the program, (resource system) and the potential users (user system) (Orlandi, Landers, Weston, \& Haley, 1990).

Acting as the innovation, the cue-based feeding protocol provided feeding knowledge and techniques to be adopted first by nurses, and then by parents. As described by the diffusion of innovations theory, the process of cue-based feeding adoption, in the NICU, was facilitated by a progressive dissemination of information, through a variety of low-tech and high-tech modalities. Therefore, diffusion of innovations theory was most evident in the phased, educational, roll-out process, for the project. Staff received education through: 1) informational articles, 2) poster presentations, 3) DCC leadership meetings, 4) on-line learning modules, 5) display cases, 6) written policy, and 7) bedside instruction, which allowed the staff to receive and process information incrementally and increased staff interest in the practice-change process.

\section{Cue-Based Feeding Models}

Neonatal studies conducted within the past decade have increasingly focused on feeding acquisition and feeding outcomes. A variety of effective, cue-based, feeding protocols from multiple disciplines have been produced: 1) nursing, 2) speech therapy, and 3) physical therapy. Three common premises were presented by studies promoting cue-based feeding protocols: 1 ) development occurs over time and involves active social interaction between caregiver and infant, 2) continuous assessment of the infant's stability and readiness is essential, and 3) intervention should be contingent upon assessment (Newland, L'Huillier, \& Petrey, 2013; Premji, McNeil, \& Scotland, 2004; Shaker, 2009). 
Cue-based feeding is a feeding method, where, the infant directs how and when it will eat by displaying specific behavioral cues and eating reflexes. Behavioral cues, such as rooting, or sucking on fingers, are also known as approach cues, where the infant indicates that it is ready to receive feeding (Shaker, 2013). Als (1982) synactive theory of development has been widely referenced in cue-based feeding protocols, because caregivers must consider both the feeding environment and the infant's ability to feed, in order to determine whether or not feeding would be appropriate, safe or successful. While earlier feeding protocols focused more on the infant's developing mechanical function of feeding, or the relationship between co-morbidities and the onset of feeding cues, later protocols have incorporated these concepts with the importance of social interaction between caregiver and infant for feeding skill development. Regardless of the origin or focus of the cue-based protocol, common goals among cue-based feeding protocols have emerged: 1) increase overall stability while supporting feeding skill development, and the safe consumption of nutrition, 2) support caregivers in competent and confident feeding of their infant, and 3) promote caregiver knowledge of the infant's feeding readiness (Shaker, 2009).

Feeding protocols evaluating the mechanics of oral feeding, and/or the physiological coordination of the suck-swallow-breathe reflex, have laid the groundwork for developmentallybased feeding programs. By examining these issues, the early feeding skills assessment (EFS) (Thoyre, Shaker, \& Pridham, 2005) and the neonatal oral motor assessment scale (NOMAS) (Bingham, Ashikaga, \& Abbasi, 2010) focused clinical attention on the emergence of feeding mechanics and the infant's ability to eat. Feeding safety was prioritized, and programs zeroed in on the appropriate age to initiate oral feedings based upon the timing of suck-swallow-breathe coordination. The oral feeding skills assessment (OFS) (Lau \& Smith, 2011), and the supporting oral feeding in fragile infants (SOFFI) (Ross \& Philbin, 2011), examined the infant's 
developmental age when feeding ability emerged and the relationship between the onset of developmental feeding cues and co-morbidities. These protocols looked more closely at the delay in feeding skill acquisition caused by prematurity-related disability and disease.

Gestational age for the initiation of feeding was emphasized as clinicians believed that the infant's ability to acquire feeding skills was a product of aging.

The newest feeding protocols have emphasized the caregiver's role in feeding skill development. The cue-based feeding protocol from Baylor University (Newland, L'Huillier, \& Petrey; 2013) incorporates the earlier priorities for feeding safety, with the findings from the Calgary Regional Neonatal Oral Feeding Protocol (RNOFP) (Premji, McNeil, \& Scotland, 2004) to emphasize the importance of the caregiver's assessment of feeding cue development. Through the use of an interdisciplinary assessment tool caregivers, would not only assess the neurologic, physiologic, and behavioral components, of feeding readiness (Pickler, 2004), but also, the quality of the subsequent feeding event (Newland, L'Huillier, \& Petrey, 2013). By assessing the feeding readiness and feeding ability, caregivers would be able to safely, and effectively guide premature infants toward achieving feeding competence. Proper, consistent assessment of feeding readiness would assist caregivers in deciding when it is appropriate to offer oral feedings to a premature infant. Additionally, as was found in the RNOFP study, and furthered by the Baylor study, active assessment of feeding readiness cues, promotes active social interaction between the caregiver and the infant, and this relationship improved feeding acquisition (Newland, L'Huillier, \& Petrey, 2013; Premji, McNeil, \& Scotland, 2004).

After a detailed review of popular cue-based protocols discussed in the literature, the project utilized the cue-based feeding model developed at Baylor University Medical Center's hospital network (Newland, L'Huillier, \& Petrey, 2013), as the framework for developing the 


\section{IMPACT OF CUE-BASED FEEDING PROTOCOL}

protocol that underpinned the feeding practice change in the NICU at CRMC (Appendix B). Several similarities existed between the Baylor NICU system and CRMC: 1) similar patient population and volume, 2) collaborative, multi-disciplinary care, 3) emphasis on promoting breast feeding, 4) emphasis on family-centered care, and parent teaching, and 5) the importance of caregiver techniques in facilitating safe feedings. Given the similarities in care environment and developmentally-based care philosophy, between Baylor and CRMC, the Baylor cue-based feeding model provided the best framework for developing a cue-based feeding practice change at CRMC. 
IMPACT OF CUE-BASED FEEDING PROTOCOL

\section{CHAPTER 3: METHODS}

The purpose of the project was to implement a cue-based feeding protocol for oral feeding initiation and progression, within the NICU at Community Regional Medical Center (CRMC), and then evaluate the impact of the cue-based feeding protocol on feeding outcomes. Following implementation of the cue-based feeding protocol, a comparison of feeding outcomes from gestational- age/ volume-driven feeding progression (pre-protocol practice), to outcomes from an infant-driven, cue-based feeding protocol (new practice), was to be completed. The purpose of a cue-based feeding protocol was to improve premature infants' feeding outcomes, primarily by decreasing the stress of oral feeding and decrease the amount of time needed for oral feeding acquisition. Additionally, by decreasing the time needed to acquire oral feeding competency, the project intended to decrease length of hospital stay, thus decreasing the length of mother-infant separation.

Due to logistical barriers and hospital-system complexities, however, the implementation of the cue-based feeding protocol was not completed in time to perform a follow-up evaluation of post-protocol feeding outcomes. Additionally, in the early phases of project development it was discovered that pre-protocol data could not be collected, so, no pre and post protocol comparison of feeding outcomes could be done. Post-protocol data collection will be initiated on June $9^{\text {th }}, 2014,1$-month following complete project implementation, and will be obtained on a monthly basis, for a 6-month and 1-year analysis of feeding outcome trends.

\section{Project description}

As previously discussed, the project was originally developed as a research study to evaluate the impact of a developmentally-based feeding protocol on feeding outcomes in a select 
IMPACT OF CUE-BASED FEEDING PROTOCOL

group of infants within the NICU. However, after entering into the CPQCC-LOS collaborative (2013), and reviewing the project's goals and objectives, the CRMC NICU medical practitioners, and leadership team, decided, that to be congruent with the upcoming CPQCC collaborative requirement for a nutritional best-practice, developmentally supportive, feeding regimen, the cue-based feeding protocol would be implemented as the NICU's new standard of practice. The project then shifted from a study performed on a selected group of patients, to a project evaluating the feeding outcomes of all patients in the NICU following a feeding practice change. The project was then designed to evaluate the implementation process for the feeding practice change, as well as, the impact of that practice change on neonatal feeding outcomes.

A developmentally (cue)-based oral feeding protocol was to be implemented in the NICU at CRMC. Approximately 1 month following protocol implementation, a pre and post protocol observational study was to be conducted, to evaluate and compare, the feeding outcomes from gestational age/volume-driven (previous) practices, with those outcomes from the infantdriven/cue-based protocol (new standard). The pre- and post-protocol comparison of outcomes was to be done in the following areas: (a) feeding readiness, (b) feeding competency, (c) feeding outcomes, and (d) length of hospital stay. Specifically, the impact of the cue-based feeding protocol was to be evaluated by the following outcomes measures: (a) decreased or no episodes of physiological stress during feedings, as evidenced by vital signs, (b) decreased or no episodes of apnea during feedings, (c) decreased or no incidences of gagging or choking during feedings, (d) increased volume/rate of milk transfer with progressive feedings, (e) decreased number of days needed to attain independent oral feeding, (f) improved weight gain, and (g) decreased length of hospital stay (Appendix D). 


\section{IMPACT OF CUE-BASED FEEDING PROTOCOL}

A total of 60 electronic records were to be reviewed, and study data collected, on a standardized data collection form (Appendix D). Two, 30-infant groups (pre- and post-protocol implementation) were to be compared on the outcome measures of interest. The sampled infants would have been stratified into gestational birth age groups: $24-29,30-33,34-36$ weeks, to allow for a more direct comparison of infants with regards to developmental progress and course of care related to physiologic needs at various developmental stages. Statistical analysis of data would have been performed using an Independent (between groups) $t$-test. The appropriateness of the Independent $t$-test was based upon: (a) two samples and a between-groups design, (b) sample sizes are equal to or greater than 30 , and (c) when the variables of interest are on interval or ratio scales. The Independent $t$-test was to be calculated using the SPSS program.

Again, due to time constraints and hospital-system barriers, the data collection process could not be completed. The critical charting and data reporting mechanisms, necessary for data collection, have been established by the project so that the originally-planned data collection, and evaluation of feeding outcomes, can be accomplished in the near future. The remaining discussion of the project methods, results, and conclusions, will not only, address the project components that were completed, but also, the process for data collection, and analysis that was not completed, but proposed by the project.

\section{Setting}

The project was conducted in the neonatal intensive care unit (NICU) at Community Regional Medical Center (CRMC). The NICU is a level III, tertiary care unit that serves a culturally diverse population within a 4-county area: 1) Fresno, 2) Madera, Kings, and 4) Tulare, and accepts patients transferred from further counties within the central region of the state of 
California. The neonatal staff is made up of multiple disciplines including, neonatology, nursing, respiratory therapy, speech and physical therapy, and social services.

\section{Population}

The patients served by the CRMC NICU, are from culturally diverse backgrounds and represent underserved, vulnerable populations (; King et al, 2007). The NICU parents have one of more of the determinants for vulnerability and health disparity as defined in the Centers for Disease Control (CDC), Health Disparities and Inequities Report (2011). The CRMC NICU primarily admits premature infants born between 24 and 37 weeks gestation. However, the NICU also accepts full term infants at greater than 37 weeks that require intensive care.

\section{Sample}

In order to accurately evaluate the factors influencing the onset, and progression of oral feeding in premature infants, the following sampling inclusion and exclusion criteria were defined by the project.

Inclusion criteria. The subjects for the project will come from the population of preterm neonates in the Neonatal Intensive Care Unit (NICU) at Community Regional Medical Center (CRMC) born between 24 to 37 weeks gestation. The neonates admitted into the NICU will either be born at CRMC or transferred in from an outlying facility. Infants eligible for the retrospective, evaluation of feeding outcomes, post-protocol implementation, will meet the following criteria: (a) infants who are admitted to the CRMC NICU who are born between 24-37 weeks gestation, (b) infants who have achieved at least 32 weeks postmenstrual age (PMA), (c) intermediate/routine care and are deemed "feeder/growers" (as evidenced by decreasing IV fluids, increasing enteral feedings, showing cues for oral feeding), (d) infants not receiving advanced respiratory/ventilator support via mechanical ventilator or continuous positive airway 


\section{IMPACT OF CUE-BASED FEEDING PROTOCOL}

pressure (Bubble, CPAP, SiPAP, HFNC $>3 \mathrm{~L} / \mathrm{min}$ ), and (e) infants not receiving inotrope medication infusions for cardiovascular/blood pressure support.

Exclusion criteria. Infants not eligible for the evaluation of feeding outcomes would be excluded based upon the following criteria: (a) Infants who have not achieved at least 32 weeks postmenstrual age, (b) Infants who regardless of postmenstrual age require critical care, (c) Infants who remain on advanced respiratory/ventilator support via mechanical ventilator or continuous positive airway pressure (Bubble CPAP, SiPAP, HFNC >3L/min), and (d) Infants who remain on inotropic medication for cardiovascular/blood pressure support.

Variables of interest. The pre- and post- protocol groups of infants will be compared on the following variables of interest: (a) gestational age at birth/admission to the NICU, (b) postmenstrual age (PMA) at which enteral feeds were initiated, (c) post-menstrual age (PMA) at which full enteral feeds were achieved, (d) post-menstrual age (PMA) at which oral feeds were first initiated, (e ) post-menstrual age (PMA) at which full oral feeds were achieved and maintained, (f) number of incidents of apnea/bradycardia/desaturation during oral feedings (daily total), (g) number of incidents of gagging/choking during oral feeding (daily total), (h) weight at discharge, and (i) post-menstrual age (PMA) at discharge ( Appendix D).

\section{Project components}

The project was composed of 4 major components: 1) electronically formatted cue-based feeding flow sheet (Appendix E), 2) oral feeding data report (Appendix F), 3) staff education (Appendix G), and 4) cue-based feeding unit policy (Appendix H). Each project component was developed individually, then, implemented in total, as a feeding practice change in the NICU.

Electronic charting. In order to document an infant's readiness to orally feed, or quality of the feeding events, changes needed to be made to the electronic health record (EPIC). Since 


\section{IMPACT OF CUE-BASED FEEDING PROTOCOL}

the practice of cue-based feeding was being introduced by the project, cue-based feeding information was not being captured in the current charting. Improved electronic charting was an essential component of the project, because without it, nurses could not document important feeding information, nor could providers obtain feeding data that would allow them to develop appropriate feeding plans.

The Baylor cue-based feeding model (Newland, L'Huillier, \& Petrey, 2013)(Appendix B) provided the conceptual framework for the CRMC feeding readiness assessment template that was developed and built into the EPIC charting system (Appendix E). The feeding readiness assessment was designed to allow nurses to assess, evaluate (score), and document, the infant's behavioral cues for feeding readiness. Based upon the readiness assessment, the nurse would determine the appropriateness of offering oral feeding either by bottle or by breast feeding with the mother. The readiness assessment, would allow nurses to evaluate (score) the quality of the oral feeding event, and determine whether or not, the feeding was a safe and positive experience for the infant.

As a result of the charting changes implemented by the project, nurses have begun to chart feeding readiness, and feeding event details including: 1) the length of time needed to feed, 2) caregiver techniques used to make the feeding event safe, and 3) any interruptions of the feeding, such as apnea or bradycardia. The ongoing assessments and evaluations of feeding readiness and quality have allowed both nurses and providers to begin recognizing the earliest onset of feeding cues, as well as, the earliest indicators of feeding acquisition and maintenance, which are critical criteria for discharge to home (AAP, 2008).

Feeding data report. An initial data inquiry from CRMC's Health Information Management (HIM) department revealed that the pre-project charting was devoid of detailed oral 
IMPACT OF CUE-BASED FEEDING PROTOCOL

feeding data. A data collection form (Appendix D) was submitted to HIM upon receiving Investigative Review Board (IRB) approval, and this investigator was informed that the requested data could not be obtained and/or tabulated into a report, because it was not being captured in the electronic health record. A review of existing maternal-child database reports, including reports that originated in the NICU, and reports that originated in another maternalchild department, but contained NICU data, showed that no comprehensive reports on the acquisition of oral feeding were being collected (Appendix F).

Therefore, a report collecting the specific data relating to oral feeding acquisition and quality would have to be built as well. To collect the feeding acquisition outcome data needed for the project, a report was formatted to capture data documented in the feeding readiness assessment template that was also being built. This investigator collaborated with the corporate informatics personnel to format a data report that was based upon the outcomes measures listed on the project's original data collection form (Appendix D). The data report file, titled OB119 was developed to show statistics tracking the initiation, progression, and outcomes related to oral feeding of NICU (Appendix F).

Staff education. Staff education on cue-based feeding was delivered incrementally through a variety of teaching modalities. Staff education was the first project component to be initiated. Cue-based feeding education began with a needs assessment survey 1-year prior to the initiation of the project. During an annual skills competency day in November 2012, nursing staff members were asked to respond to a survey assessing knowledge of, and interest in, cuebased feeding practices. From the results of the staff survey an electronic file of cue-based articles was established for staff members to read at their leisure. From the articles collected for 
IMPACT OF CUE-BASED FEEDING PROTOCOL

the reading file, an article titled "What is Cue-Based Feeding?" was written by this investigator and delivered electronically, in the NICU quarterly newsletter, Developmental Times.

In October 2013, during the next annual skills competency day, the nursing staff was given a poster board presentation about the origins, research evidence, and benefits of cue-based feeding. During the presentation, staff was provided with an overview of the cue-based feeding protocol and the project components needed for implementing a practice change. A question and answer session and post-test followed the poster presentation.

By March and April of 2014, nursing staff completed their cue-based feeding education through on-line, corporate Health Learning Center (HLC) modules (Appendix G). The course titled "Cue-based Feeding of Premature Infants" was composed of 4 modules: 1) gestational development of feeding behavior cues, 2) CRMC cue-based feeding protocol, research evidence, and benefits of practice change, 3) educating parents on feeding cue recognition, and appropriate feeding techniques, and 4) electronic charting (EPIC) changes. Each learning module included a post-test, and staff members were required to complete the education prior to the electronic charting "going live".

Cue-based feeding policy. The final project component implemented was a policy addressing cue-based feeding (Appendix H). A review of current NICU policies revealed that no policy specifically guiding oral feeding practices of premature infants existed in the unit. A policy outlining evidence-based purpose and procedures related to cue-based feeding was developed in collaboration with the CRMC neonatal nurse practitioners (NNP). The cue-based feeding policy: 1) defined both feeding cues and stress cue, 2) provided guidelines for assisting mothers with breast feeding, 3) outlined the cue-based protocol built into the electronic health record (EPIC), 4) provided guidelines for the safe removal or reinstitution of tube feeding, 5) 
provided guidelines for practitioners to order appropriate developmentally-based feeding progression plans, and 6) recommended appropriate topics for parent teaching. The policy was reviewed and approved by the medical oversight committee, comprised of the NICU's neonatologists, NNPs, and administrative team. The approval of the cue-based feeding policy on April $8^{\text {th }}, 2014$ by the NICU medical oversight committee signaled the completion of the final project component.

\section{Data collection}

As previously discussed, data collection post-protocol implementation could not be completed. A pre- and post-protocol comparison could also not be done because of the nonexistence of pre-protocol feeding outcome data. The following discussion of data collection, and data analysis, addresses the data collection process as it was originally intended, and how it will occur as a result of project implementation.

The form attached in Appendix C, represents, the CPQCC checklist for baseline data collection that was initiated August 8, 2013, per CPQCC guidelines. The CPQCC checklist, hand recorded by staff, established baseline parameters for initiating, and evaluating, best practices in the 3 previously mentioned care areas specified by the CPQCC collaborative. The data collected by the CPQCC checklist (Appendix C) was used by this researcher as a starting point for development of the data collection form for the project (Appendix D). In terms of feeding data, the CPQCC checklist focused on recording information related to the initiation and acquisition of feedings by tube. It did not address the infant's transition from tube feeding to oral feeding or the outcomes related to oral feeding acquisition.

The data collection form represented in Appendix D was designed to collate and code the electronic data (captured from the electronic health record [EPIC]) specifically related to oral 
feeding acquisition and oral feeding outcomes. The project feeding data collection form (Appendix D) does include feeding related information collected by the CPQCC checklist (Appendix C) so that the infant's entire feeding history can be recorded. The data collection form (Appendix D) was also used to format a data report titled OB119 (Appendix F) that will show statistics tracking the initiation, progression, and outcomes related to oral feeding of NICU patients. Thus, instead of a hand review of individual charts using individual data collection forms (Appendix D), the variables of interest for feeding outcomes (contained on the original data collection form) will be presented in report OB119.

The data collection captured by the form in Appendix C has been ongoing since August 2013, and the data collection captured by the form in Appendix D, and presented in the OB119 report will commence 1-month post implementation of the project, on June $9^{\text {th }}, 2014$. The project implementation is considered finalized on May $9^{\text {th }}, 2014$ at which point all staff members would have completed relevant education and practice on the new electronic charting that is capturing cue-based feeding data. Data models cannot begin to be generated until the charting has been used for at least 1-month, making the June $9^{\text {th }}, 2014$ deadline the first viable opportunity for post-protocol data collection.

\section{Data analysis plan}

As outlined in the original project proposal, two groups of infants (pre and post protocol implementation) were to be compared on the variables of interest (Appendix D). The sampled infants were to be stratified into gestational birth age groups: $24-29,30-33,34-36$ weeks, to allow for a more direct comparison of infants with regards to developmental progress and course of care related to physiologic needs at various developmental stages. During the initial development of the project it was discovered that oral feeding acquisition and outcome data (pre- 


\section{IMPACT OF CUE-BASED FEEDING PROTOCOL}

protocol) could not be collected because of electronic charting deficiencies. The variables of interest related to feeding outcomes, were not being captured in the existing charting. These deficiencies prompted the development of the OB119 feeding data report. Therefore, instead of a pre-and post-protocol comparison as originally proposed, outcomes from a 6-month and 1-year protocol follow-up will be compared. The infants will still be compared on the variables of interest, and stratified into the appropriate gestational birth age groups.

The statistical analysis will be performed using an Independent (between groups) $t$-test. The appropriateness of the Independent $t$-test is based upon: (a) two samples and a betweengroups design, (b) sample sizes are equal to or greater than 30 , and (c) when the variables of interest are on interval or ratio scales. The Independent $t$-test will be calculated using the SPSS program. The value for significance will be reported in SPSS using Levene's Test for Equality of Variance (F). Significance for Levene's test is greater than .05. In order to compare two groups of infants at 6-months and 1-year, 2 OB119 feeding reports will run. These reports will tabulate the number of instances for each variable of interest and sort by gestational birth age group. The tabulated numbers generated in each report can then be statistically compared.

The sample size of 30 (6-month post-protocol) and 30 (1-year post-protocol) was selected because the independent (between groups) $t$-test has a greater ability to detect variances with sample sizes of 30 or greater. Also, a previous 6-month review (August 2013 to January 2014) of average NICU unit census for admissions, of infants born between 24 and 37 weeks gestation, showed that approximately half of the total unit population (approximately 30 ) had met the inclusion criteria for the study. The review of the unit census showed that each day there were infants that would transition from critical care to routine care, having achieved at least 32 weeks PMA, weaned from critical oxygen support, inotropic medication, and introduced to oral feeding. 
IMPACT OF CUE-BASED FEEDING PROTOCOL

So each day, infants were meeting the inclusion criteria for the study facilitating a sampling of 30 infants before and after protocol implementation.

\section{Ethical consideration}

All electronic data will be requested from CRMC's Health Information Management (HIM) department and the de-identified information will be electronically tabulated and organized into the feeding outcome report OB119. All data will be kept in a locked office on a password protected computer at CRMC and will only be accessible to the project investigator. If needed, all data can be transcribed to the data collection form (Appendix D) and given unique study numbers. The data collection forms will not contain any patient identifiable information and all paper copies of the data will be destroyed upon the completion of the study. The 6-month post-protocol infants will be identified as 1 to 30 , and the 1 -year post-protocol infants will be identified as 31 to 60 . This investigator completed coursework verifying competency in the protection of human subjects prior to implementation of the project to ensure proper protection of patient information.

\section{Summary}

The purpose of the project was to implement a cue-based feeding protocol for oral feeding initiation and progression, within the NICU at Community Regional Medical Center (CRMC), and then evaluate the impact of the cue-based feeding protocol on feeding outcomes. Following implementation of the cue-based feeding protocol, a comparison of feeding outcomes from gestational- age/ volume-driven feeding progression (pre-protocol practice), to outcomes from an infant-driven, cue-based feeding protocol (new practice), was to be completed. As a feeding practice change, the cue-based feeding protocol was implemented with goals to improve premature infants' feeding outcomes, and decreased the infant's length of hospitalization. 
IMPACT OF CUE-BASED FEEDING PROTOCOL

Multiple components, such as electronic charting, feeding policy, staff education and data reports, required complete development in order to fully implement the project,

Logistical barriers and hospital-system complexities, however, prevented the implementation of the cue-based feeding protocol in time to perform a follow-up evaluation of post-protocol feeding outcomes. Additionally, because of an inability to collect pre-protocol oral feeding data, and pre-and post-protocol comparison was not possible. Post-protocol data collection will be initiated after June $9^{\text {th }}, 1$-month following complete charting implementation, and obtained on a monthly basis, for a 6-month and 1-year follow-up analysis of feeding outcomes.

The remaining discussion in this manuscript will address the barriers that prevented timely implementation of the cue-based feeding protocol, and present solutions for anticipating and overcoming those barriers. 
IMPACT OF CUE-BASED FEEDING PROTOCOL

\section{CHAPTER 4: RESULTS}

Because the cue-based feeding project was not completely implemented in time to perform a post-protocol evaluation of feeding outcomes, and the absence of pre-protocol data prevented a pre- and post-protocol comparison of feeding outcomes, no data models or data analysis will be presented at this time. Post-protocol data collection will be initiated after June $9^{\text {th }}, 2014,1-$ month following complete project implementation, and will be obtained on a monthly basis, for a 6-month and 1-year analysis of feeding outcome trends.

\section{Statistical analysis}

The originally planned statistical analysis was an Independent (between groups) $t$-test to compare two groups of 30 infants (pre- and post-protocol implementation) on the variables of interest (Appendix D). The same statistical analysis will be done on two groups of 30 infants (6month and 1-year) post-protocol. The sampled infants will be stratified into gestational birth age groups: $24-29,30-33,34-36$ weeks, to allow for a more direct comparison of infants with regards to developmental progress and course of care related to physiologic needs at various developmental stages. The appropriateness of the Independent $t$-test is based upon: (a) two samples and a between-groups design, (b) sample sizes are equal to or greater than 30 , and (c) when the variables of interest are on interval or ratio scales. The Independent $t$-test will be calculated using the SPSS program. The value for significance will be reported in SPSS using Levene's Test for Equality of Variance (F). Significance for Levene's test is greater than .05.

Again, since data collection could not be completed as a result of project implementation barriers, no statistical analysis will be presented here.

\section{Discussion}


IMPACT OF CUE-BASED FEEDING PROTOCOL

The project presented in this manuscript was due, in part, to satisfy requirements for the completion of the doctor of nursing practice (DNP) degree, and in part, to fulfill mandates from the California Perinatal Quality Care Collaborative (CPQCC). As previously discussed, the project was originally developed as a research study to evaluate the impact of a developmentallybased feeding protocol on feeding outcomes in a select group of infants within the NICU. However, after entering into the state-mandated, CPQCC-LOS collaborative, and reviewing the project's goals and objectives, the CRMC NICU medical practitioners, and leadership team, decided, that to be congruent with the upcoming CPQCC collaborative requirement for a nutritional best-practice, developmentally supportive, feeding regimen, the cue-based feeding protocol would be implemented as the NICU's new standard of practice. The project then shifted from a study performed on a selected group of patients, to a project evaluating the feeding outcomes of all patients in the NICU following a feeding practice change.

Implementation of cue-based feeding as a practice change meant increasing the size and scope of the project, and developing infrastructure for documentation and data collection. Additionally, a unit policy addressing oral feeding practices needed to be developed and approved. Staff education regarding all project components needed to be developed, approved, and disseminated. During the development and implementation of the project, multiple unit- and corporate-level barriers and challenges were encountered. Given the DNP program time constraints for project implementation, and the complex nature of project review and approval by nursing leadership, final data collection and analysis could not be completed. Although the project did produce valuable instruments for recording and measuring feeding outcomes in the future, the delays in the implementation process did not allow for feeding outcome evaluation at the conclusion of the project. 
The remaining discussion will address the system and nursing leadership challenges that hindered timely project implementation. A review of unit- and corporate-level barriers, encountered during the project, including recommendations for improving the implementation process for future project endeavors will conclude this manuscript.

\section{Limitations and barriers}

Electronic charting limitations. Building the cue-based feeding protocol into the electronic health record (EPIC) was singularly, the most complex, time-consuming, component of the project. Having the appropriate charting was not only important for documentation purposes, to allow nurses to chart cue-based feeding events, but it was critical for data acquisition. It was discovered early on in the project's development, that, large gaps existed in feeding data, particularly, oral feeding information, because the desired information was not being captured in the current charting system. Therefore, in order to capture the appropriate feeding data, the NICU charting needed to be changed. Furthermore, the cue-based feeding charting was central to the project, where implementation of the other project components: unit policy, data report, and nursing education, hinged upon its completion.

In June 2013, when the NICU entered into the CPQCC-LOS collaborative, it was discovered that the capability to collect detailed feeding data was lacking, due to charting deficiencies. A leadership team developed a process for collecting baseline data for the collaborative, but found that only enteral (tube) feeding data could only be retrieved from EPIC. The gaps in the feeding data-set also required that data collection for the collaborative be done on paper (Appendix C), as, there was no electronic reporting matrix linked to the charting. The data parameters established by the NICU leadership did address early acquisition of tube feeding, but did not address transition from tube feeding to oral feeding, or, complete acquisition of oral 
IMPACT OF CUE-BASED FEEDING PROTOCOL

feeding. Therefore, the history of oral feeding initiation and acquisition was not being actively collected. The cue-based feeding project required that the oral feeding history be retrievable from EPIC. In order to collect data on the desired oral feeding outcome measures established by the project (Appendix D), the EPIC charting needed to be revised, so that the appropriate information was distinctly captured by documentation.

Unit-level barriers. The process to build the appropriate charting into EPIC took $71 / 2$ months, which was twice as long as expected. The proposed charting needed to be reviewed by multiple layers of nursing leadership both inside and outside of the NICU. From initiation to completion, the proposed charting build moved through the following phases for approval and review: 1) presentation of proposed build to NICU leadership team, 2) development of charting template, 3) presentation of charting template to other maternal-child departments, 4) submission of charting template to corporate information systems staff for official build into EPIC, 5) new charting test phase, and 6) production/go live.

The first significant barrier in the build process was establishing the initial meeting with the nurse-manager overseeing EPIC charting in the NICU. As a night-shift nurse, scheduling a meeting with a manager that worked a traditional 8 to 5 schedule was more difficult than anticipated. It was not unusual to find the manager's daily schedule filled with meetings, which required looking several weeks ahead to find an opening. In addition to conflicts in work schedules, the meetings that were established were frequently cancelled by the manager, because of other priorities. At the outset, this investigator began to feel resistance coming from a nursing leader in the unit. Despite multiple attempts to communicate with the manager through email, voicemail, or text, little cooperation was given until the unit director was involved in the process. This barrier to participation was definitely counter to what Kanter (1993) described as 


\section{IMPACT OF CUE-BASED FEEDING PROTOCOL}

organizational empowerment, where access to information, resources, and support through a shared power structure improves employee performance and system functioning.

As a staff member, it was difficult to effectively engage in the decision-making process for the project, due to a lack of opportunities to collaborate with the nurse manager (Scott \& Caress, 2005). Not being part of the leadership team, and having to be inserted into the leadership routine, there was a palpable incongruence between being a staff member and nurse leader (Hurley \& Linsley, 2007). The initial lack of cooperation from the nurse manager definitely created the impression that nursing leadership is a culture of exclusivity, and that, nurse leaders, work in silos, rather than in teams. The opportunity to engage with the nurse manager came as a result of a completely unrelated project, where this investigator offered assistance to the manager. Through cross-pollination, and juxtaposing unrelated projects, a meeting established to discuss one of her projects led to a discussion of the cue-based feeding project and the EPIC charting build (Porter-O'Grady, \& Malloch, 2011).

Once a planning schedule was established with the nurse manager, the next set of challenges involved moving the proposed charting template forward through the remaining maternal-child departments, such as labor and delivery, and newborn nursery. This required attending multiple meetings to network with nurses and technical personnel from other departments. Since maternal-child departments share portions of EPIC charting, nurses from the other departments expected to weigh-in on the charting proposed by the NICU, even though the charting had no bearing on the care in other departments and would not be utilized by them. While moving the proposed charting template through the various phases of approval, opportunities to collaborate with other staff members and nurse leaders were created. Garnering the opinions and perspectives of others, and responding quickly to questions and concerns with 
IMPACT OF CUE-BASED FEEDING PROTOCOL

reliable evidence, created more interest in the implementation of the charting build, and caused a shift in this investigator's role from staff participant to team leader (Schulman, 2001).

Corporate-level barriers. The final set of hurdles for the proposed EPIC charting was the corporate-level build process. Again, establishing a meeting schedule with the information systems personnel was difficult. Given their responsibility for all charting changes and computer updates for the entire 3-hospital corporation, corporate information specialists were scarcely available. Additionally, during the time that the NICU charting template was submitted, Joint Commission was performing surveys, and corporate computer updates were being initiated. Therefore, the charting needs of the NICU were not viewed as an immediate priority. Estimated timelines for completions were often quoted then extended. Fortunately, a great deal of progress was made through e-mail communication. Again, collaboration and cross-pollination were techniques that allowed for more efficient problem-solving. A team leader role also allowed for more direct communication with nurse-resources and corporate decision-makers, making the decision-making process more efficient. To maintain any forward progress for the project, this investigator moved from working the night shift, to a corporate, daytime schedule during the final 2 months of implementation.

The final challenge to complete the NICU cue-based feeding charting was the testing process. The test phase allowed users to trial the proposed charting for actual use. In order to test a proposed build, access must be granted to a tester. Nursing managers typically have automatic access to Sand Box, which is the cyber-test world for trialing EPIC charting changes. Access to test the new charting required a written request from the NICU director, and took 3 weeks to grant. While in test, the charting was reviewed daily for formatting, spelling errors, and function. Working a daytime schedule allowed for more direct involvement in the project's 
IMPACT OF CUE-BASED FEEDING PROTOCOL

progress, as well as, daily testing and daily feedback from information system technicians.

Though the proposed charting only spent a short time ( 2 weeks) in the test phase, the 3-week delay just to trial the charting was an additional hindrance to finalizing the charting implementation in a timely manner.

\section{Recommendations}

Though the project did generate a great deal of interest and support within the NICU, there were still barriers to implementation. Ironically, the anticipated barrier of resistance to practice change from nurses and physicians, did not come to fruition, however, unforeseen barriers at the nurse leadership level did occur. Given what has been learned throughout the project process, several recommendations for implementing future projects have been considered.

As previously discussed, the changes to the EPIC charting system was a prolonged process at 71/2 months, and was initially met with resistance from the nurse manger with whom this investigator was required to work. Rather than embrace collaboration to work together on the project, the nurse manager initially adopted an isolationist approach. Working directly with nurse leaders during the project implementation, it became apparent that the nurse manager's initial avoidance of the project was probably due more in part to having an excessive workload. Effective nurse leaders are necessary to address complex issues associated with healthcare systems, however, increasing corporate pressures, are overburdening nursing leadership with a complexity of tasks (Hurley \& Linsley, 2007; Macphee, Skelton-Green, Bouthillette, \& Suryaprakash, 2012).

Empowerment theories, both psychological and structural, (Kanter, 1993 and Spreitzer, 1995) have been associated with enhanced nurse and nurse leader outcomes. Structural 


\section{IMPACT OF CUE-BASED FEEDING PROTOCOL}

empowerment, an organizational theory based on Kanter's (1993) work, posits the importance of obtaining access to organizational empowerment structures that provide advancement opportunities, and access to information, support, and resources. Nurse leaders can create empowering work environments for themselves and staff nurses by removing barriers to organizational empowerment structures and streamlining organizational systems and processes (Laschinger et al, 2009). For example, by identifying key stakeholders to participate in a project review, and eliminating unnecessary layers of administration, reduces extraneous or redundant input, and decreases the time it takes to move that project forward through the corporate system. Empowering work environments are most effectively created through the process of sharing power by way of equitable resource allocation, enhanced communication, and participatory decision-making (Yukl, 2006). As nurse leaders share power, they may find that they can share the workload. By distributing projects to staff members, nurse leaders can gain valuable input from staff members, provide leadership training to staff members, and improve staff members' sense of competence and influence in the practices in the unit (Spreitzer, 1995). Shared governance, based on a collaborative, decentralized style of management, gives staff and leadership collective responsibility and accountability for practice and process decisions, and facilitates more efficient, creative work flows (Scott \& Caress, 2005).

Nurse leaders must to re-learn how to collaborate. When overburdened with corporate policies, initiatives, and tasks, it becomes easier for nursing leaders to simply complete the work themselves, rather than seek out others to assist them in accomplishing their goals. Lack of collaboration gives the impression that nursing leadership is exclusive, which runs completely counter to the natural tendencies of nursing. Collaboration and cross-pollination are techniques where nurse leaders could bring people together to create solutions. Problem solving would be 


\section{IMPACT OF CUE-BASED FEEDING PROTOCOL}

accomplished through a team-oriented, multi-disciplinary approach, a more inclusive leadership approach (Porter-O'Grady \& Malloch, 2011). Collaboration and cross-pollination p are problem-solving methods that are more effective, creative, time- and energy-saving than working alone.

To maximize the success of a project it is critical to immediately identify champions for change. Champions for change are key individuals who can provide leadership and resources to a project and are usually in decision-making positions and can therefore streamline any approval process. The champions for the NICU cue-based feeding project were: 1) the NICU medical director, 2) the NICU administrative director, and 3) a clinical mentor and neonatal nurse practitioner (NNP). Each of them provided expertise that facilitated implementation of specific components of the project, and collectively they provided the momentum to keep the project moving forward. Without their investment in the project, each component of the project would have been bogged down by complex processes and redundant systems. Additionally, their leadership status placed them in positions of influence to obtain buy-in from their colleagues.

\section{Conclusion}

The cue-based feeding project was not only a genuine opportunity to initiate nurse-driven change in practice, to promote improved patient outcomes, but, it was also a profound learning experience in leadership techniques and leadership process. In order to promote a feeding practice change among nurses and providers, a more global view of the unit and the hospital had to be adopted. The project allowed this investigator to gain a greater understanding of unit and hospital systems, leadership structure, policy writing, informatics, and curriculum development.

During the project development and implementation process, there was definitely a shift in mindset from bedside nurse to nurse leader. The bedside nurse, as described by Rogers (1983) 


\section{IMPACT OF CUE-BASED FEEDING PROTOCOL}

is typically the end-user, (part of the user system), receiving policies, technology, and practice changes, whereas the nurse-leader is part of the resource system responsible for disseminating the policies, technology, and so forth. In the transition from an end-user to a distributer, this investigator had to consider the stakeholders, policies, procedures, education and systems involved in the process of practice change. Implementation of cue-based feeding as a practice change meant increasing the size and scope of the original project, and developing infrastructure for documentation and data collection. Additionally, a unit policy addressing oral feeding practices needed to be developed and approved by nursing management and medical oversight. Staff education regarding all project components needed to be developed, approved, and disseminated.

The layers of nursing leadership, and the protracted process of project approval, at both the unit and hospital levels, were significant barriers to timely project implementation (PorterO'Grady \& Malloch, 2011). Leadership techniques of collaboration, cross-pollination, identifying key stakeholders, and champions for change, were critical to overcome barriers to project implementation. Given the DNP program time constraints for project implementation, and the complex nature of project review and approval by nursing leadership, final, post-protocol data collection and analysis could not be completed. Thus the delays in project implementation did not allow for oral feeding outcome evaluation, as originally proposed, however, the project did produce valuable instruments for recording and measuring feeding outcomes in the future.

Future plans for project follow-up have been established by NICU nursing leadership. As a result of the documentation and data infrastructure that has been established by the DNP cuebased feeding protocol project, data for 6-month and 1-year feeding outcomes will be collected and evaluated, with the intention to present results to: 1) CRMC corporate leadership, 2) CPQCC 
IMPACT OF CUE-BASED FEEDING PROTOCOL

1-year collaborative follow-up (June 2014); and 3) Central Valley Nursing Research Conference 2015. In addition, CRMC corporate leadership in charge of the health record (EPIC) system has requested this investigator's participation in the EPIC End-User Group committee, to develop a protocol for workflow impact secondary to EPIC charting changes. The leadership has requested that the implementation process used for establishing the cue-based feeding charting, as well as the data on feeding outcomes, be used to develop a template for a program to measure true impact of electronic charting on nursing workflows and patient outcomes. 
IMPACT OF CUE-BASED FEEDING PROTOCOL

\section{References}

Als, H., \& Brazelton, T.B. (1981). A new model of assessing the behavioral organization in preterm and fullterm infants. Journal of the American Academy of Child Psychiatry. 20, 239263.

Als, H., Duffy, F.H., McAnulty, G.B. (1996). Effectiveness of individualized neurodevelopmental care in the newborn intensive care unit (NICU). Acta Paediatrica Supplement. 416, 21-30.

Als, H. \& Gilkerson, I. (1995). Developmentally supportive care in the neonatal intensive care unit. Zero to Three. $15(6), 3-10$.

American Academy of Pediatrics (2008). American Academy of Pediatrics hospital discharge of the high-risk neonate. Pediatrics, 122, 1119-1126.

Arvedson, J., Clark, H., Lazarus, C., Schooling, T., \& Frymark, T. (2010). Evidence-based systematic review: Effects of oral motor interventions on feeding and swallowing in preterm infants. American Journal of Speech-Language Pathology. 19,321-340.

Bandura, A. (1977). Self-efficacy: toward a unifying theory of behavior change. Psychological Review, 84, 191-215.

Bandura, A. (1982). Self-efficacy mechanism in human agency. American Psychologist, 37, $122-147$.

Bertoncelli, N., Cuomo, G., Cattani, S., Mazzi, C., Pugliese, M., Coccolini, E., Zagni, P., 
IMPACT OF CUE-BASED FEEDING PROTOCOL

Mordini, B., \& Ferrari, F. (2012). Oral feeding competence of healthy preterm infants:

A review. International Journal of Pediatrics, 1-4.

Bingham, P.M., Ashikaga, T., \& Abbasi, S. (2010). Relationship of neonatal oral motor assessment scale to feeding performance of premature infants. Journal of Neonatal

Nursing. 18, 30-36.

Bregman, J. (1998). Developmental outcome in very low birth weight infants: current status and future trends. Pediatric Clinics of North America. 45, 637-690.

Bhutta, A.T., Cleves, M.A., Casey, P.H., Cradock, M.M., \& Anand, K.J. (2002). Cognitive and behavioral outcomes of school-aged children who were born preterm: a meta-analysis. JAMA. 288, 2542-2543.

California Perinatal Quality Care Collaborative (CPQCC) and California Children's Services (CCS) (2013). Optimizing Length of Separation (LOS) Collaborative. Meeting convened in Sacramento, California June 7, 2013.

Centers for Disease Control and Prevention (2011). Health Disparities and Inequalities Report-

United States. Retrieved August 21, 2012 from

\section{hitp://www.cde.gov/minorityhealth/OMHHE.html}

Crowe, L., Chang, A., \& Wallace, K. (2012). Instruments for assessing readiness to commence suck feeds in preterm infants: effects on time to establish full oral feeding and duration of hospitalization. Cochrane Database Systematic Reviews[online], 18(4). 


\section{IMPACT OF CUE-BASED FEEDING PROTOCOL}

Coughlin, M., Gibbins, S., \& Hoath, S. (2009). Core measures for developmentally supportive care in neonatal intensive care units: theory, precedence and practice. Journal of Advanced Nursing. 65(10), 2239-2248.

Hamilton, B.E., Martin, J.A., \& Sutton, P.D. (2004). Center for Disease Control and PreventionNational Center for Health Statistics. Births: preliminary data for 2003. National Vital Statistics Report. 53(9), 1-17.

Hurley, J. \& Linsley, P. (2007). Leadership challenges to move nurses toward collaborative individualism within a neo-corporate bureaucratic environment. Journal of Nursing Management. 15, 749-755.

Jacobs, S., Sokol, J., \& Ohlsson, A. (2002). The newborn individualized developmental care and assessment program is not support by meta-analyses of the data. Journal of Pediatrics. 140, 699-706.

Kanter, R. (1993). Men and Women of the Corporation. New York, NY: Basic Books.

King, T.E., \& Wheeler, M.B. (2007). Applying interactive health technologies for vulnerable populations. In Piette, J.D., \& Schillinger, D. (Eds)., Medical Management of Vulnerable and Underserved Patients (pp. 131-138). New York, NY: McGraw-Hill.

Laschinger, H., Finegan, J., \& Wilk, P. (2009). Context matters. The impact of unit leadership and empowerment on nurses' organizational commitment. Journal of Nursing Administration, 39(5), 228-235. 
IMPACT OF CUE-BASED FEEDING PROTOCOL

Lau, C. \& Hurst, N. (1999). Oral feeding in infants. Current Problems in Pediatrics. 29, 105124.

Lau, C., \& Smith, E. O. (2011). A novel approach to assess oral feeding skills of preterm infants. Neonatology, 100(1), 64-70.

Lee, Y.S., Garfield, C., Kim, H.N. (2012). Self-efficacy theory as a framework for interventions that support parents of NICU infants. $20126^{\text {th }}$ International Conference on Pervasive Computing Technologies for Healthcare (PervasiveHealth) and Workshops.

DOI 10.4108/icst.pervasivehealth.2012.248710

MacPhee, M., Skelton-Green, J., Bouthillette, F., \& Suryapraksh, N. (2011). An empowerment framework for nursing leadership development: supporting evidence. Journal of Advanced Nursing, 26, 1-12.

McCain, G.C., \& Gartside, P. (2002). Behavioral responses of preterm infants to a standard care and semi-demand feeding protocol. Newborn and Infant Nursing Reviews. 2, 187-193.

McGrath, M., \& Sullivan, M. (2002). Birth weight, neonatal morbidities, and school age outcomes in full term and preterm infants. Issues Comprehensive Pediatric Nursing. 25, 231-254.

Melnyk, B.M., \& Cole, R. (2011). Generating evidence through quantitative research. In Melnyk, B.M., \& Fineout-Overholt, E. (Eds). Evidence-Based Practice in Nursing \& Healthcare. (2 $2^{\text {nd }}$ ed., 397-433). Philadelphia, PA: Wolters Kluwer/Lippincott Williams \& 
IMPACT OF CUE-BASED FEEDING PROTOCOL

Wilkins.

Melnyk, B.M., Feinstein, N.F., Alpert-Gillis, L., Fairbanks, E., Crean, H.F., Sinkin,R.A., Stone, P.W., Small, L., Tu, X., \& Gross, S. (2006). Reducing premature infants' length of stay and improving parents' mental health outcomes with the creating opportunities for parent empowerment (COPE) neonatal intensive care unit program: a randomized, controlled trial. Pediatrics.118, 1413-1427.

Miles, M.S., \& D’Auria, J. (1994). Parenting the medically fragile infant. Capsules Comments In Pediatric Nursing. 1, 2-14.

Miles, M.S., Holditch-Davis, D., Burchinal, P., \& Nelson, D. (1999). Distress and growth outcomes in mothers of medically fragile infants. Nursing Research. 48, 129-140.

National Association of Neonatal Nurses (NANN), (2013). Infant-directed oral feeding for premature and critically ill hospitalized infants: Guideline for practice. National Association of Neonatal Nurses. 1-17.

Newland, L., L'Huillier, M.W., Petrey, B. (2013). Implementation of cue-based feeding in a level III NICU. Neonatal Network. 32(2), 132-137.

Orlandi, M.A., Landers, C., Weston, R., \& Haley, N. (1990). Diffusion of Health Promotion Innovations. In Glanz, K., Lewis, F.M., Rimer, B.K. (Eds). Health Behavior and Health Education: Theory, Research, and Practice. San Francisco, CA: Jossey-Bass. 
IMPACT OF CUE-BASED FEEDING PROTOCOL

Oldenburg, B., Hardcastle, D. M., \& Kok, G.. (1997). Diffusion of Innovations. In Glanz, K., Lewis, F.M., Rimer, B.K. (Eds). Health behavior and health education. ( $2^{\text {nd }}$ ed., pp. $270-$ 286). San Francisco, CA: Jossey-Bass Publishers.

Pickler, R.H. (2004). A Model for Feeding Readiness for Preterm Infants. Neonatal Intensive Care. 17(4), 31-36.

Pickler, R.H., Frankel, H.B., Walsh, K.M., \& Thomson, N.M. (1996). Effects of nonnutritive sucking on behavioral organization and feeding performance in preterm infants. Nursing Research. 45,132-135.

Premji, S.S., McNeil, D.A., \& Scotland, J. (2004). Regional neonatal oral feeding protocol:

Changing the ethos of feeding preterm infants. Journal of Perinatal \& Neonatal Nursing. $18(4), 371-384$.

Porter-O'Grady, T., \& Malloch, K. (2011). Quantum Leadership: Advancing Innovation, Transforming Health Care. ( $3^{\text {nd }}$ ed) Sudbury, MA: Jones \& Bartlett Learning.

Pridham, K., Kosorok, M.R., Greer, F., Kayata, S., Bhattacharya, A., \& Grunwald, P.C. (2001). Comparison of caloric intake and weight outcomes of an ad lib feeding regimen for preterm infants in two nurseries. Journal of Advanced Nursing. 35, 751-759.

Rogers, E. M. (1983). Diffusion of Innovations. (3 ${ }^{\text {rd }}$ ed.) New York, NY: Free Press.

Ross, E. S., \& Philbin, M. K. (2011). Supporting oral feeding if fragile infants (SOFFI). Journal of Perinatal and Neonatal Nursing. Retrieved September 15, 2012 from: 
IMPACT OF CUE-BASED FEEDING PROTOCOL

www.jpnnjournal.com.

Schraeder, B.D., Heverly, M.A., O’Brien, C., \& Goodman, R. (1997). Academic achievement and educational resource use of very low birth weight (VLBW) survivors. Pediatric Nursing. 23(44), 21-25. Cue-based feeding is a feeding method, where, the infant directs how and when it will eat by displaying specific behavioral cues and eating reflexes.

Schulman, J. (2001). "Thinking upstream" to evaluate and to improve the daily work of the newborn intensive care unit. Journal of Perinatology. 21, 307-311.

Scott, L., \& Caress, A.L. (2005). Shared governance and shared leadership: meeting the challenges on implementation. Journal of Nursing Management. 13, 4-12.

Shaker, C. S. (2012). Feed me only when I'm cueing: Moving away from a volume-driven culture in the NICU. Neonatal Intensive Care. 25, 27-32.

Shaker, C. S. (2013). Cue-based feeding in the NICU: Using the infant's communication as a guide. Neonatal Network. 32(6), 404-408.

Speitzer, G. (1995). Psychological empowerment in the workplace: dimensions, measurement, and validation. The Academy of Management Journal, 38(5), 1442-1465.

Thoyre, S. M. (2006). Feeding outcomes of extremely premature infants after neonatal care. JOGNN. 36, 366-376.

Thoyre, S.M., \& Brown, R. L. (2004). Factors contributing to preterm infant engagement during bottle feeding. Nursing Research. 53(5), 304-313. 
IMPACT OF CUE-BASED FEEDING PROTOCOL

Thoyre, S.M., Shaker, C.S., \& Pridham, K.F. (2005). The early feeding skills assessment for preterm infants. Neonatal Networks. 24, 7-16.

Westrup, B. (2007). Newborn individualized developmental care and assessment program (NIDCAP)-family-centered developmentally supportive care. Early Human Development. 83,443-449.

Yukl, G. (2006). Leadership in Oragnizations, $\left(6^{\text {th }}\right.$ ed) . Upper Saddle River, NJ: Pearson Education International. 
IMPACT OF CUE-BASED FEEDING PROTOCOL

APPENDICES 
IMPACT OF CUE-BASED FEEDING PROTOCOL

APPENDIX A

COVER LETTER 


\section{IMPACT OF CUE-BASED FEEDING PROTOCOL}

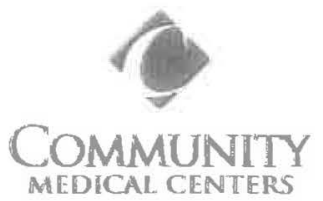

January 24, 2013

Lindsay Newland, BSN, RM, IBCLC

5999 CR 166

Kaufman, TX 75142

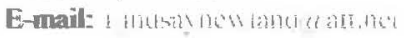

Dear Lindsay,

I am writing you to thank you for sharing your work on cue-based feeding in the neonatal intensive care unit. I became interested in your study, Implensentation of Cue-Rased Feeating ìn a Level III NKCU, this past June when I reviewed a power-point presentation of your protocol given to me by one of our speech therapists Taylor Leech, after she received it at the Nationsl Association of Neonatal Therapists (NANT) conference in Fort. Worth, Texas in May, 2012. I have been extensively reviewing cue-based feeding protocols for a project for my doctorate nursing practice (DNP) degree. After presenting multiple cuebesed feeding protocols to the NICU staff att Community Regional Medical Center (CRMC) during annual skills renewal this past October, 2012, the overwhelming staff interest was in the protocol that you developed for your study.

In our comespondence I have learned how similar our NICU populations, envinomment, and care philosophies are. I would like to use your protocol as the foundation for developing a project that will impleanent a cue-based feeding practice change in our NICU. The assessment and care principles encapsulated in your protocol would provide the basis for charting, unit-policy, and feeding practice changes. If for any reason you should change your mind about allowing us to reproduce your protocol for our cue-based practice change, please contact me. Otherwise, I will andicipate moving ahead with my cue-based protocol project. My contact information is (559) $970-5356$ (cellular) or via email at

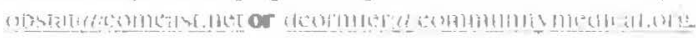

Again, 1 thank you for your time and information,

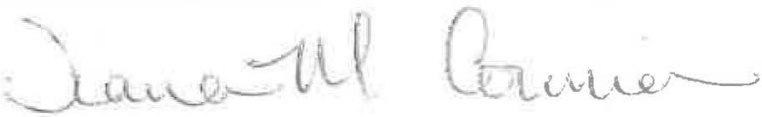

Diana M. Cormier, MPH, RN-BSN, RNC 
IMPACT OF CUE-BASED FEEDING PROTOCOL

APPENDIX B

CUE-BASED FEEDING PROTOCOL 
IMPACT OF CUE-BASED FEEDING PROTOCOL

Cue-Based Feeding Scales (Newland, L'Huillier, \& Petrey, 2013)

1) Readiness 2) Quality Bottle 3) Quality Breast Feeding 4) Caregiver Techniques

Oral Feeding Readiness Assessment Scale

\begin{tabular}{|c|c|c|}
\hline Evaluation & Score & Description \\
\hline $\begin{array}{l}\text { Ready to Bottle or } \\
\text { Breast Feed }\end{array}$ & 1 & $\begin{array}{l}\text { Drowsy, alert or fussy prior to care. Rooting and/or hands to mouth / takes } \\
\text { pacifier. Good tone. "Ohh face" }\end{array}$ \\
\hline $\begin{array}{l}\text { Ready to Bottle or } \\
\text { Breast Feed }\end{array}$ & 2 & $\begin{array}{l}\text { Drowsy or alert once handled. Some rooting or takes pacifier. Adequate } \\
\text { tone. }\end{array}$ \\
\hline $\begin{array}{l}\text { Limited Bottle/Breast } \\
\text { or NNBF }\end{array}$ & 3 & Briefly alert with care. No hunger behaviors. No change in tone \\
\hline $\begin{array}{l}\text { Limited Bottle/Breast } \\
\text { or NNBF }\end{array}$ & 4 & Sleeping throughout care. No hunger cues. No change in tone. \\
\hline Gavage Only & 5 & $\begin{array}{l}\text { Needs increased } \mathrm{O} 2 \text { with care. A/B with care. Tachypnea over baseline with } \\
\text { care. }\end{array}$ \\
\hline
\end{tabular}

Quality Bottle Feeding Assessment Scale

\begin{tabular}{lcl}
\hline Evaluation & Score & Description \\
\hline Bottling Well & 1 & Nipples with a strong coordinated suck throughout feed. \\
Bottling Fair & 2 & $\begin{array}{l}\text { Nipples with a strong coordinated suck initially, but fatigues with } \\
\text { progression. }\end{array}$ \\
Bottling Fair & 3 & $\begin{array}{l}\text { Nipples with consistent suck, but difficulty coordinating swallow; some loss } \\
\text { of liquid or difficulty pacing. Benefits from external pacing. }\end{array}$ \\
Bottling Poor & 4 & $\begin{array}{l}\text { Nipples with a weak/inconsistent suck. Little to no rhythm. May require } \\
\text { some rest breaks. }\end{array}$ \\
$\begin{array}{l}\text { Unable to Bottle } \\
\text { Safely }\end{array}$ & 5 & $\begin{array}{l}\text { Disorganized: Unable to coordinate suck/ swallow / breathe pattern or } \\
\text { significant difficulty initiating suck. Does not benefit from pacing. May } \\
\text { result in frequent or significant A/B's or large amounts of liquid loss and/ or } \\
\text { tachypnea significantly above baseline with feeding. }\end{array}$ \\
$\begin{array}{l}\text { Unable to Bottle } \\
\text { Safely }\end{array}$ & $\begin{array}{l}\text { Dysfunctional: Abnormal or deviant oral motor patterns. Unable to extract } \\
\text { fluid from nipple, flaccid jaw/tongue, inability to maintain seal or suction } \\
\text { when alert. Significant, loss of liquid from mouth. }\end{array}$ \\
\hline Quality Breast Feeding Assessment Scale
\end{tabular}


IMPACT OF CUE-BASED FEEDING PROTOCOL

\begin{tabular}{lcl}
\hline Breast Feeding Fair & 2 & $\begin{array}{l}\text { Latched well with a strong coordinated suck initially, but fatigues with } \\
\text { progression. Active suck for 8-min. }\end{array}$ \\
Breast Feeding Fair & 3 & $\begin{array}{l}\text { Difficulty maintaining a strong, consistent latch. May be able to } \\
\text { intermittently nurse but only for <8 min. }\end{array}$ \\
Breast Feeding Poor & 4 & $\begin{array}{l}\text { Latch is weak. Inconsistent with a frequent need to "re-latch". Limited effort } \\
\text { that is inconsistent in pattern. Maybe considered NNBF. }\end{array}$ \\
$\begin{array}{l}\text { Unable to Breast Feed } \\
\text { Safely }\end{array}$ & 5 & $\begin{array}{l}\text { Unable to latch to breast and achieve suck / swallow / breathe pattern. May } \\
\text { have difficulty arousing to state conductive to breastfeeding. Could result in } \\
\text { Frequent or significant A/B's and/or tachypnea significantly above baseline } \\
\text { with feeding. }\end{array}$ \\
\hline
\end{tabular}

Caregiver Techniques

\begin{tabular}{ll}
\hline Type & Description \\
\hline A & Side-Lying Position \\
B & External Pacing \\
C & Adding or Increasing $\mathbf{O} 2$ during feed \\
D & Imposed Breaks \\
E & Stimulation for recovery from As/Bs/Ds \\
F & Frequent Burping \\
H & Nipple change during feeding \\
\hline
\end{tabular}

- Increased number of caregiver techniques selected indicates less readiness to orally feed, and/or feeding that could be unsafe. 
IMPACT OF CUE-BASED FEEDING PROTOCOL

APPENDIX C

CPQCC-LOS CHECKLIST 


\section{CPQCC Length of Stay Checklist}

\section{NUTRITION}

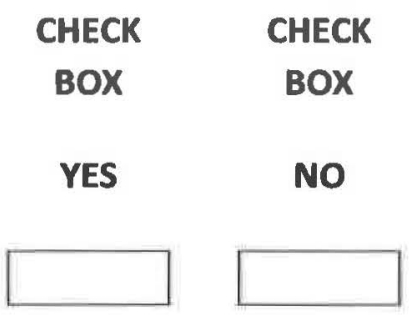

a. Feeds started within 48 hrs ( 2 days) of birth unless documentation of clinically significant hyper-Mg, intestinal dysfunction or clinical instability.
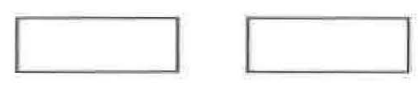

b. Full feeds (defined as no TPN) within 14 days ( 2 wks) unless documentation of clinically significant hyper-Mg, intestinal dysfunction or clinical instability

c. First attempt at PO feeds when infant can suckle vigorously on pacifier or at breast without cardiorespiratory instability.

d. Full PO feeds when no longer on gavage feeds and/or TPN

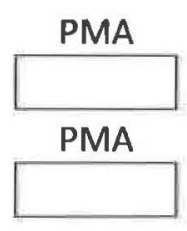

\section{DISCHARGE PLANNING}

a. On admission, Teaching Menu initiated

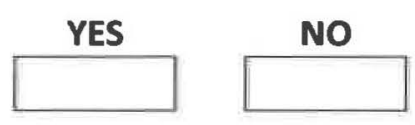

b. By PMA 35.0 weeks: (Date

i. Attempt open crib
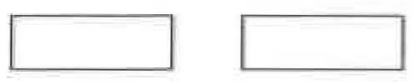

ii. Ped for home is documented in the EPIC Discharge Instructions.

iii.Breast feeds initiated and Lactation consultation follow up done.

iv. The discharge diet has been addressed. (See MD or MSRD note)
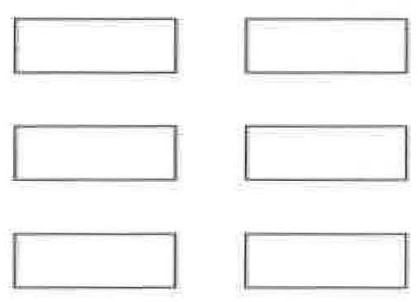

v. Parent competencies demonstrated by completion of Discharge checklist 


\section{APNEA, BRADYCARDIA, DESATURATION}

i. PMA at caffeine start (will typically be Birth GA)

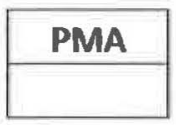

PMA

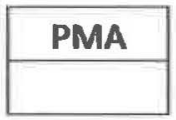

PMA

ii. PMA caffeine stop

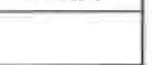

iii. If clinically significant event has occurred in previous $24 \mathrm{hrs}, \mathrm{MD} / \mathrm{NP}$ will document in Progress Notes "Apnea is active problem".

Time between most recent PN entry "Apnea is active problem" and time of discharge is less than 10 days. Check Yes or No

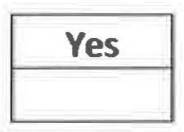

No

iv. Home apnea monitor is considered when there is significant apnea despite caffeine therapy and PMA of $\mathbf{4 4}$ weeks.

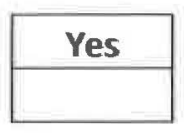

No

\section{FOLLOW UP}

Readmit within 72 hours
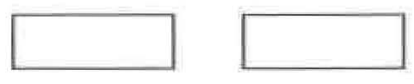

Phone follow up at $72 \mathrm{hrs}$
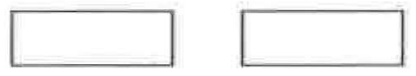

Pt Label 
IMPACT OF CUE-BASED FEEDING PROTOCOL

\section{APPENDIX D}

CUE-BASED FEEDING DATA COLLECTION SHEET 
IMPACT OF CUE-BASED FEEDING PROTOCOL

\section{CUE Based Feeding Data Collection Form}

Study ID\#: Gestational age on admission:

Total DOS/LOS (calculated in days):

Feeding Method: $\square$ Volume-driven (current practice) $\square$ Cue-based (infant driven, practice change)

PMA for enteral feeds initiated: PMA for full enteral feeds achieved:

PMA for oral feeds initiated:

PMA for achievement of full oral feeds maintained (no longer needing gavage feeds):

PMA when advanced supplemental oxygen support (Bubble CPAP or High Flow Nasal Cannula @ greater than 3 liters/minute) was discontinued:

Number of incidents that disrupt oral feedings (daily totals):

$\square$ Apnea, \#:

$\square$ Bradycardia, \#:

$\square$ Desaturation, \#:

$\square$ Gagging, \#:

$\square$ Choking, \#:

Weight at discharge:

PMA at discharge: 
IMPACT OF CUE-BASED FEEDING PROTOCOL

\section{APPENDIX E}

ELECTRONIC CHARTING (EPIC) 
This is the old workflow.

Old workflow has the formula display name and choices of EBM/SSC 27 (HMF 2/50 with SSC 30).

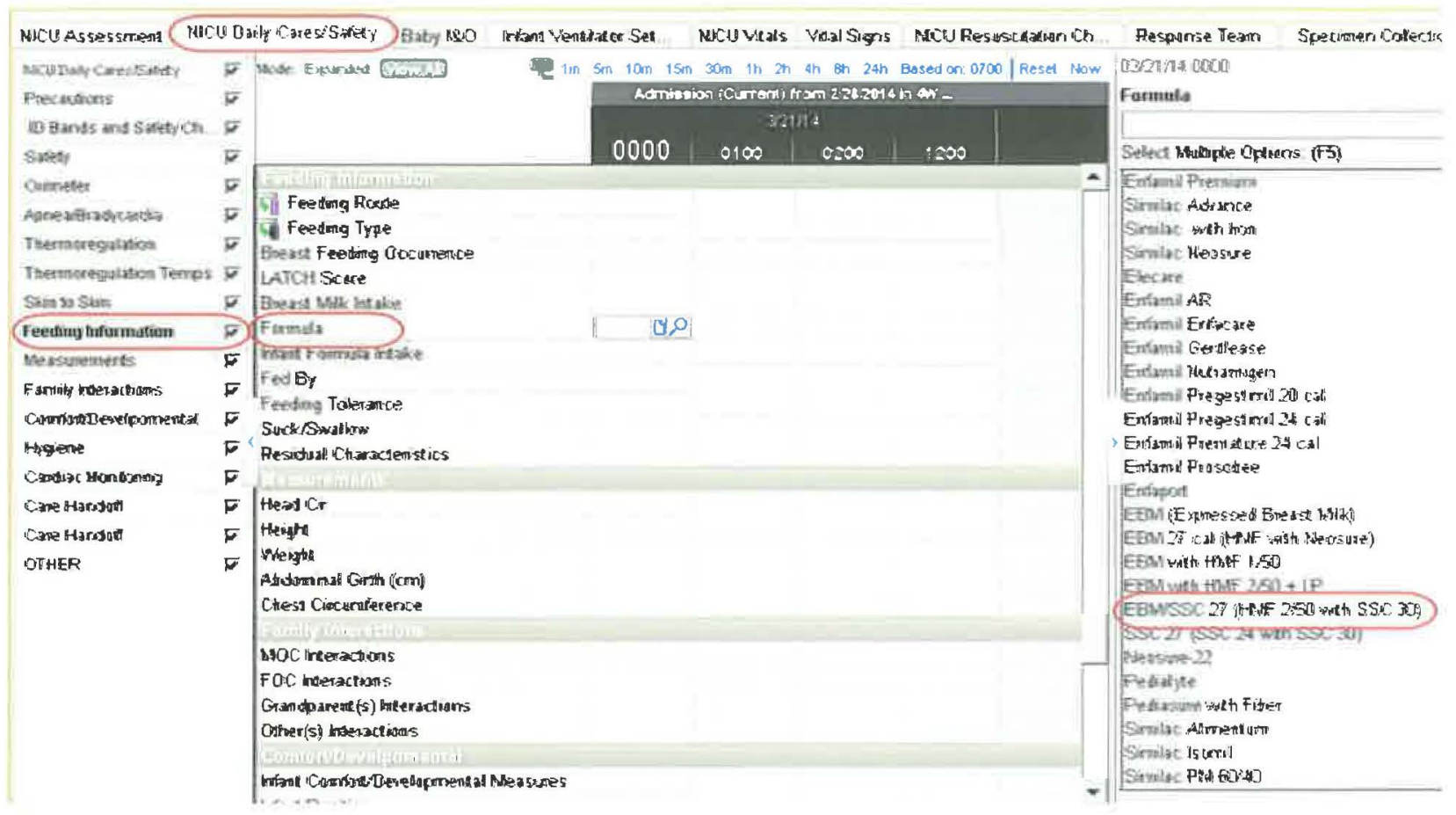

New workflow: This is the new Flowsheet group.

\begin{tabular}{|c|c|c|}
\hline Precautions & $\sqrt{\sigma}$ & Mode: Expanded Micwatin \\
\hline 10 Bands and Safety & $\sqrt{2}$ & 䆓 $1 \mathrm{~m} 5 \mathrm{~m} \quad 10 \mathrm{~m}$ 15m $30 \mathrm{~m}$ 1h $2 \mathrm{~h}$ \\
\hline Safety & $\sqrt{\sigma}$ & \\
\hline Oximeter & $\bar{N}$ & \\
\hline Apnea Bradycardia & $\sqrt{2}$ & Feeding Readiness Assessment \\
\hline Thermoregdation & $\vec{F}$ & Readiness \\
\hline Themnareg dation Temps & $\sqrt{7}$ & Quality Boltle \\
\hline Induced Hypothermis & $\vec{a}$ & Quality Breast \\
\hline Hypothermia Care & $\overrightarrow{\mid}$ & Caregiver Techniques \\
\hline Skin to Skin & $\vec{\square}$ & Duration of Feeding (min) \\
\hline Phototherany & 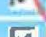 & Number of Apnea/Bradycardia Events \\
\hline & $N$ & Feeding Intormation \\
\hline Feeding Readiness A... & 6) & 57] Feeding Route \\
\hline Feeding Information & F & 5il Feeding Type \\
\hline Measurements & F & Fed By \\
\hline Family luteractions & F & Feeding Tolerance \\
\hline Comfot Develpomental & F & Suck/Swallow \\
\hline Hygiene & $\bar{\sigma}$ & Measurements \\
\hline Lise Calbration & $\sqrt{ }$ & Head Cir \\
\hline Sambiar Mnnitmina & $\sigma$ & Height \\
\hline
\end{tabular}

Update the display name for formula row to Nutrition type and also add new three new types of Nutrition type for donor express breast milk and also remove EBM/SSC 27 (HMF 2/50 with SSC 30) type. 


\section{IMPACT OF CUE-BASED FEEDING PROTOCOL}

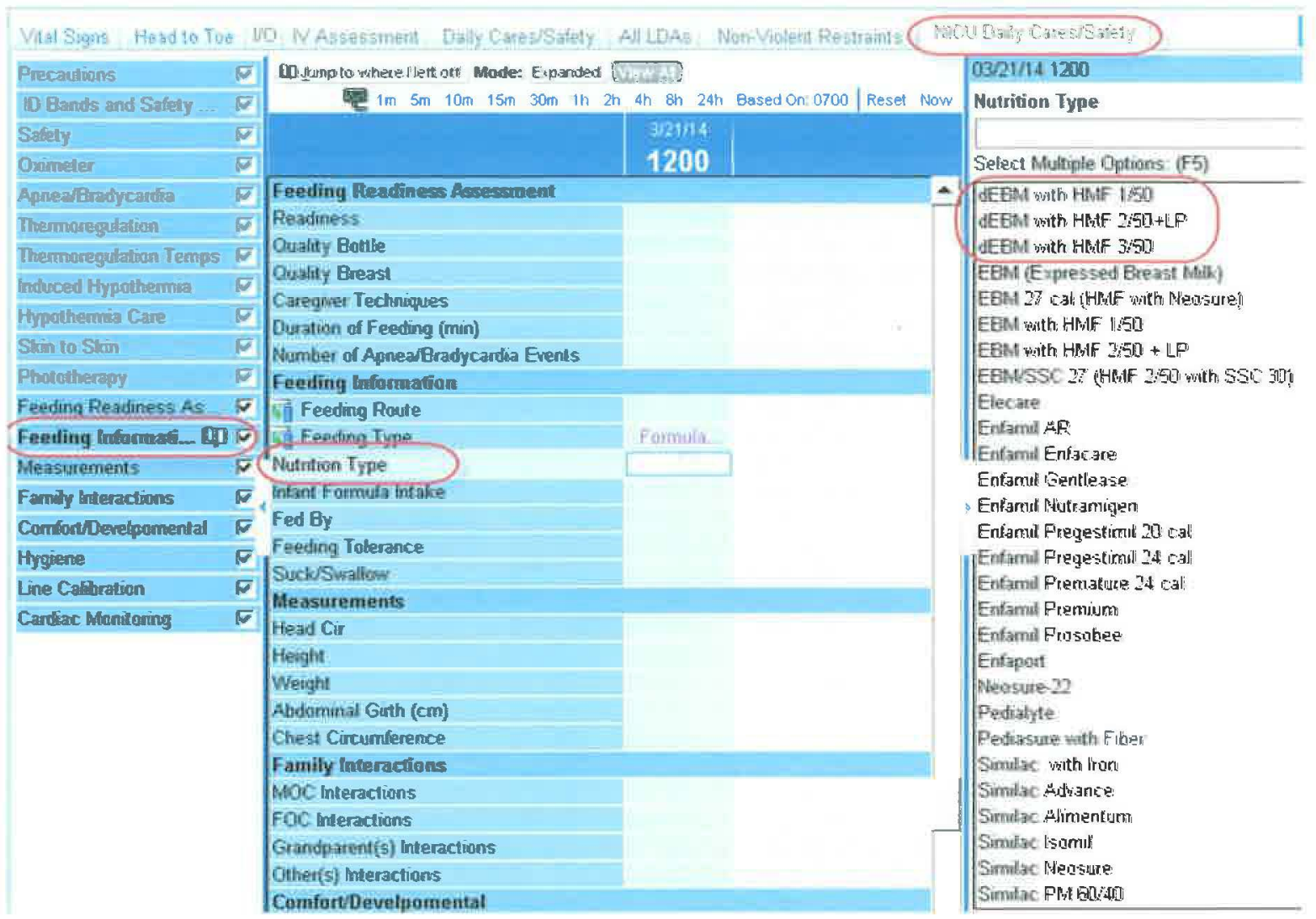

These are the new Feeding Readiness Assessment rows with the choices that are available to choose from.

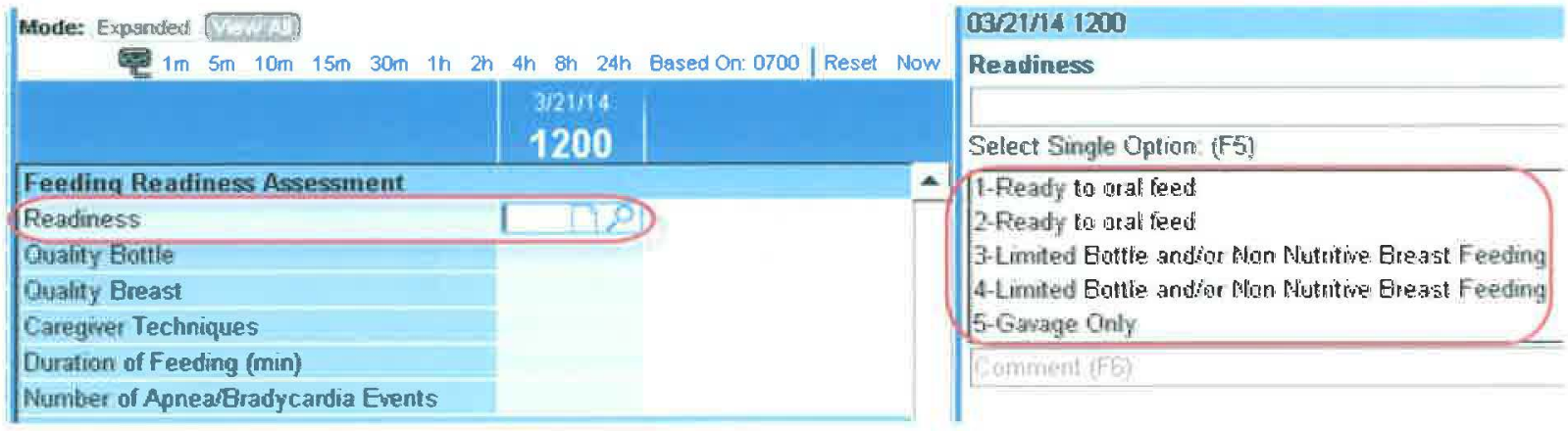

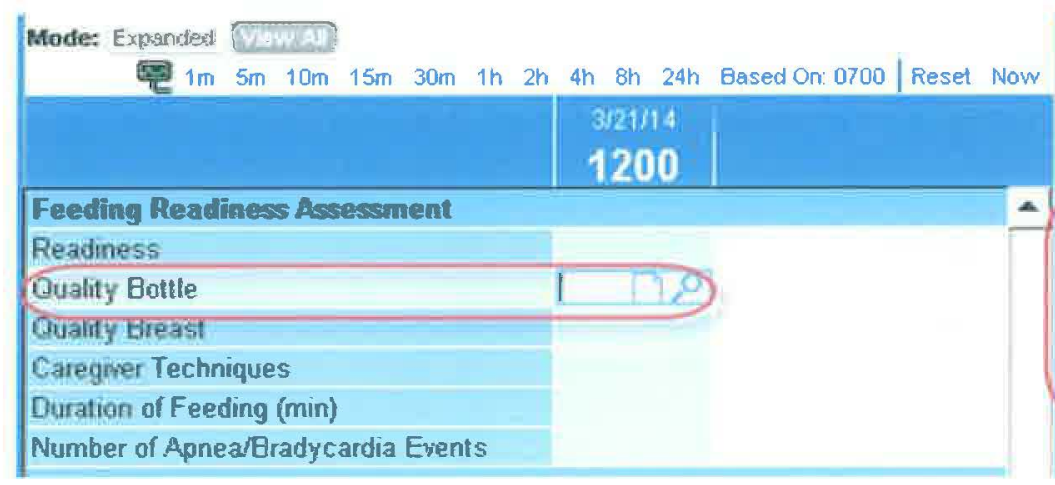

\begin{tabular}{l} 
0921/4 1200 \\
Ouality Botte \\
\begin{tabular}{|l} 
Select Single Option: (F5) \\
1-Botting Whell \\
2. Bottling Fair \\
3- Bottling Fair \\
4-Bottling Poor \\
5-Unable to bottle safely \\
6-Unable to bottle safely
\end{tabular} \\
\hline
\end{tabular}




\section{IMPACT OF CUE-BASED FEEDING PROTOCOL}

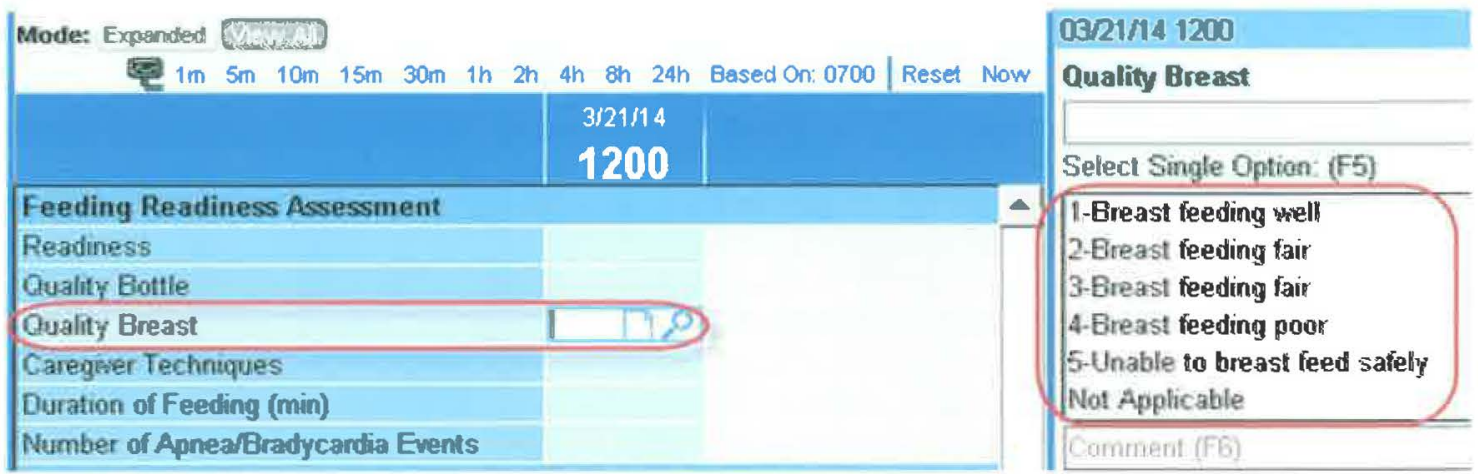

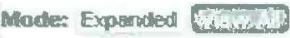

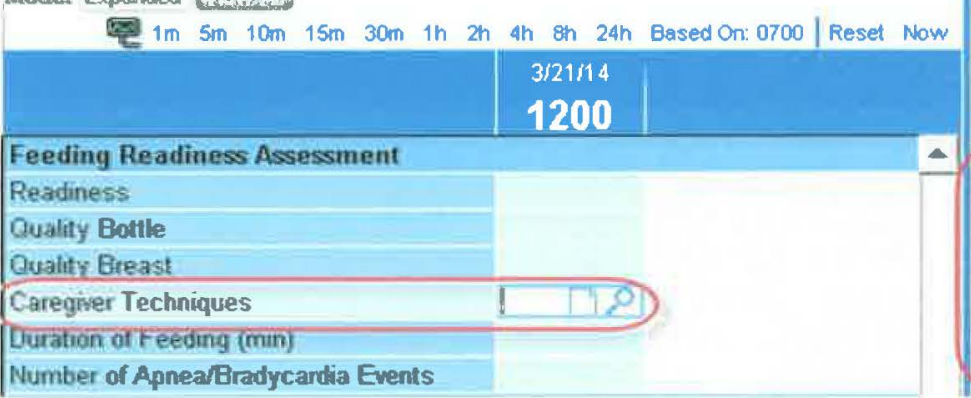

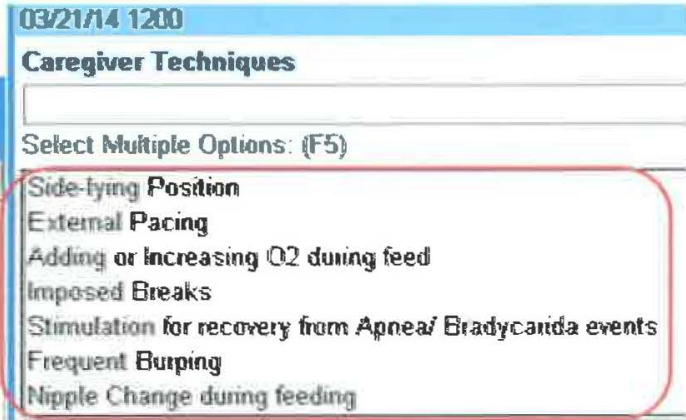

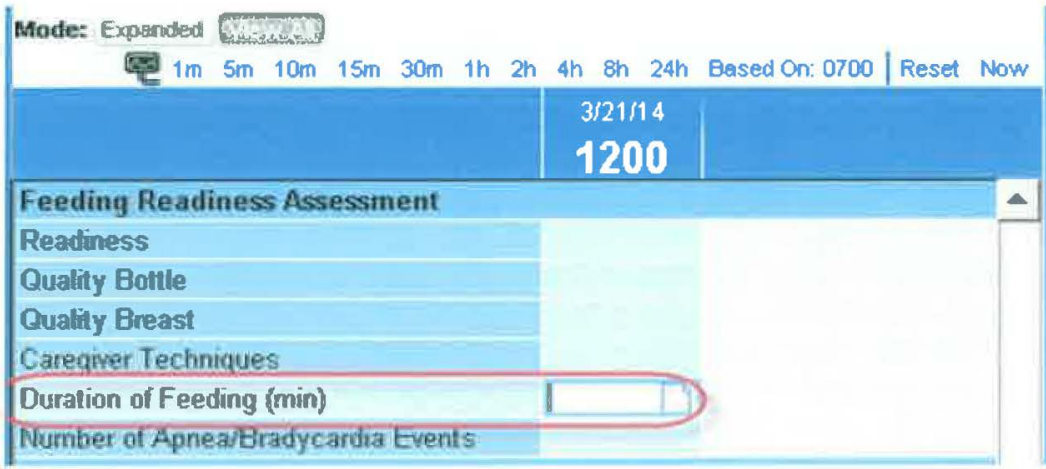

$03 / 21 / 41200$

Duration of Feeding (min)

Comment $(F 6$

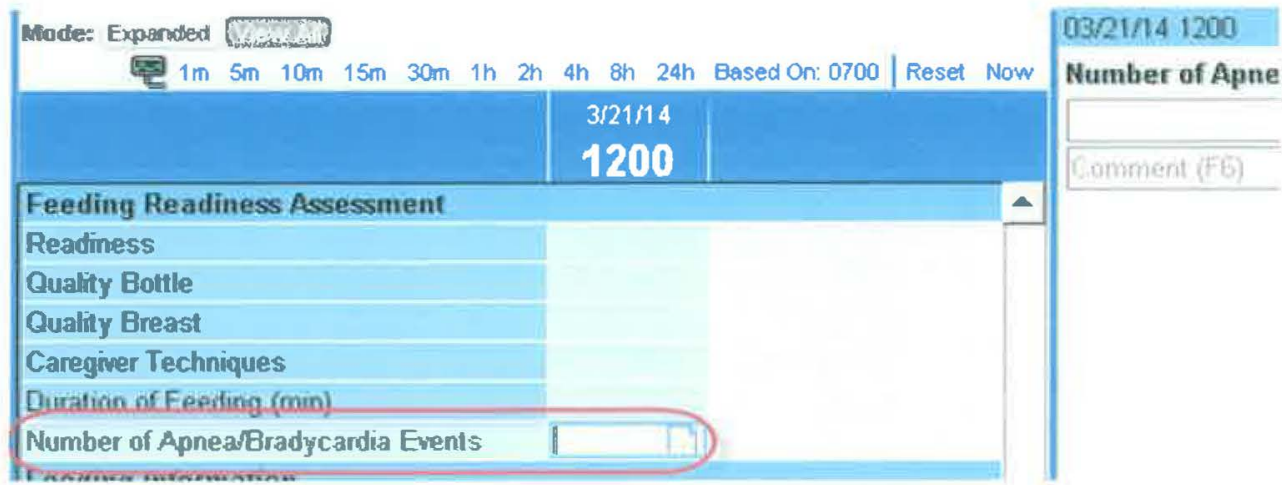


IMPACT OF CUE-BASED FEEDING PROTOCOL

\section{APPENDIX F}

SUMMARY OF NICU DATA REPORTS 


\section{NICU Database Reports}

The following reports are those that originate in the NICU, and are dedicated to NICU patient data. The reports are formatted specifically from data points captured in NICU charting. No feeding data reports, except the newly developed OB119.

\begin{tabular}{|c|l|}
\hline ID NUMBER & REPORT DESCRIPTION \\
\hline OB008 & $\begin{array}{l}\text { NICU CPQCC Data Collection: This report shows mother and child information for births } \\
\text { between } 400 \text { grams and } 1500 \text { grams and/or gestational age between } 22 \text { and } 30 \text { weeks. } \\
\text { OB009 }\end{array}$ \\
\hline NICU Log: This report shows monthly logs of admissions to the NICU. \\
\hline OB032 & $\begin{array}{l}\text { NICU PICCs, Umbilical lines, Foleys, and Broviacs: This report shows a count of different } \\
\text { LDAs within a selected date range for NICU departments. } \\
\text { admission and birth time for patients admitted to the NICU department. }\end{array}$ \\
\hline OB052 & $\begin{array}{l}\text { CCS NICU Stats: This report shows delivery statistics for live births and NICU admits. } \\
\text { Births and admits are broken down into different groups for birth weight and gestational } \\
\text { age. }\end{array}$ \\
\hline OB080 & $\begin{array}{l}\text { NICU Admission by Weight and GA: This report shows admissions to the NICU by weight } \\
\text { and gestational age. }\end{array}$ \\
\hline OB106 & $\begin{array}{l}\text { NICU Patient Who Received Antibiotics: This report shows NICU patient encounter } \\
\text { information for patients who received antibiotics while in the NICU. }\end{array}$ \\
\hline OB107 & $\begin{array}{l}\text { NICU Transfers LOS: This report shows information about inbound transport NICU } \\
\text { patients at CRMC. }\end{array}$ \\
\hline OB109 & $\begin{array}{l}\text { NICU Log of Admits: This report shows a log of NICU admits to CRMC who were admitted } \\
\text { with an accommodation code of NSY Level } 4 \text { intensive care 1:1 or 1:2. }\end{array}$ \\
\hline OB119 & $\begin{array}{l}\text { NICU Cue-Based Feeding: This report will show statistics tracking the initiation, } \\
\text { progression and outcomes related to oral feeding of NICU patients. }\end{array}$ \\
\hline
\end{tabular}

OB119-Data report developed by the cue-based feeding project. This report will show statistics tracking oral feeding initiation, progression and outcomes. 


\section{Shared Database Reports (Inclusive of NICU)}

The following reports are those that could be inclusive of NICU data, but could have been originated by another department in the Maternal-Child network. No feeding data reports.

\begin{tabular}{|c|l|}
\hline ID NUMBER & REPORT DESCRIPTION \\
\hline OB015 & $\begin{array}{l}\text { APGARS of } 6 \text { or less @ } 5 \text { minutes, } 28 \text { weeks or more GA: This report shows deliveries } \\
\text { where the infant's APGAR scores are } 6 \text { or less at } 5 \text { minutes, gestational age is } 28 \text { weeks } \\
\text { or greater. }\end{array}$ \\
\hline OB017 & $\begin{array}{l}\text { Deliveries Less Than } 35 \text { weeks: This report shows deliveries where the gestational age } \\
\text { was less than } 35 \text { weeks. }\end{array}$ \\
\hline OB018 & $\begin{array}{l}\text { Neonatologist Attendance on Treatment Team, Less Than } 28 \text { Weeks GA: } \\
\text { This report shows deliveries where the gestational age was less than } 28 \text { weeks, and if a } \\
\text { neonatologist was part of the treatment team. }\end{array}$ \\
\hline OB022 & $\begin{array}{l}\text { Respiratory Therapists Attended Deliveries: This report shows all deliveries where the } \\
\text { patient had respiratory therapy. }\end{array}$ \\
\hline OB041 & $\begin{array}{l}\text { CMC Preterm Deliveries (Live Births): This report shows totals and percentages by } \\
\text { provider for: total live deliveries where the gestational is less than 38 weeks. }\end{array}$ \\
\hline OB 042 & $\begin{array}{l}\text { Babies Born With Congenital Anomalies: This report shows patients who were born in } \\
\text { the organization with a congenital anomaly. }\end{array}$ \\
\hline
\end{tabular}

\section{Maternal-Child Database (Exclusive of NICU)}

The following reports are the only reports in the Maternal-Child Departments that track feeding rates, or any information related to infant feeding. Feeding data reported on term, breast feeding infants only.

\begin{tabular}{|c|l|}
\hline ID NUMBER & REPORT DESCRIPTION \\
\hline OB060 & $\begin{array}{l}\text { Exclusive Breast Milk Feeding For Couplets: This report shows exclusive breast milk } \\
\text { feeding rates for mother-baby couplets in } 3^{\text {rd }} \text { floor maternal-child units, post-partum, } \\
\text { Labor and Delivery and Nursery. }\end{array}$ \\
\hline OB060a & $\begin{array}{l}\text { Exclusive Breast Milk Feeding For Couplets: This report shows exclusive breast milk } \\
\text { feeding rates for mother-baby couplets in } 3^{\text {rd }} \text { floor maternal-child units, post-partum, } \\
\text { Labor and Delivery and Nursery. }\end{array}$ \\
\hline OB066 & $\begin{array}{l}\text { Exclusive Breast Milk Feeding For Couplets: This report shows exclusive breast milk } \\
\text { feeding rates for mother-baby couplets in } 3^{\text {rd }} \\
\text { Labor and Delivery and Nursery. }\end{array}$ \\
\hline
\end{tabular}


IMPACT OF CUE-BASED FEEDING PROTOCOL

APPENDIX G

CORPORATE ON-LINE CUE-BASED FEEDING EDUCATION 
IMPACT OF CUE-BASED FEEDING PROTOCOL

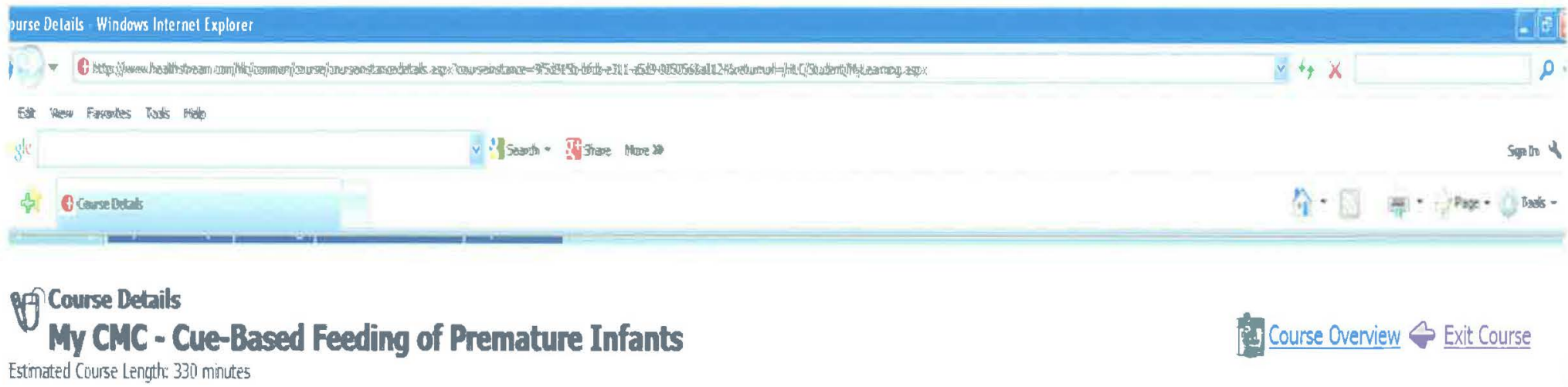

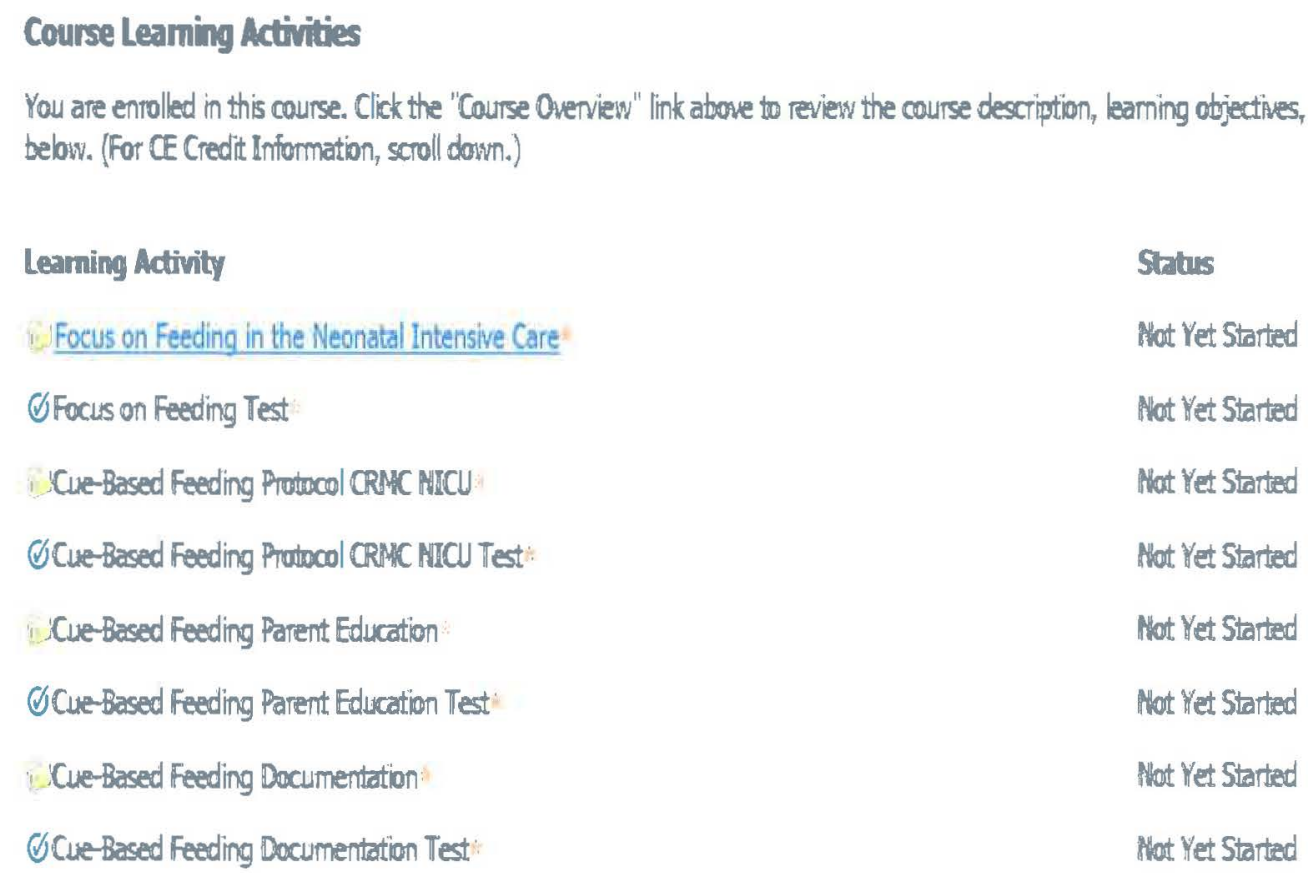

\section{Course Continuing Education Credit}

Cred its are based on State and license Discipline information. Please read through all credit information before clicking the Enroll In this Course button. education course for Cue-Based Feeding Project (4 modules with post-tests). 
IMPACT OF CUE-BASED FEEDING PROTOCOL

APPENDIX H

NICU CUE-BASED FEEDING POLICY 


\section{IMPACT OF CUE-BASED FEEDING PROTOCOL}

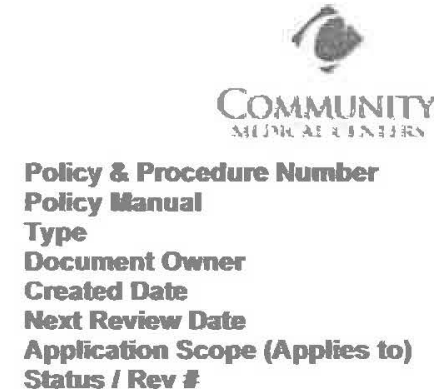

\section{PURPOSE}

A. To provide and promote standardization of safe, developmentally-based, oral feeding practices for irfants in the Neonatal Intensive Care Unit (NICU).

B. To outline and define developmentally appropriate guidel ines for transitioning infants from orogastric/nasogastric feeding tubes to oral feeding-

C. To establish developmentally appropriate criteria for assessing an infant"s readiness to initiate oral feedings and progress toward oral feeding competence (refer to Developmental Care policy)

D. To provide a framework in which the process of delivering feedings is structured to support the individualized needs of the developing infant and family.

E. To support a process of oral feeding that facilitates both bottle and breast feeding-

$\mathbb{F}$. To provide standardized guidelines for removal or retum of tube feeding as the infant's condition warrants (refer to Gavage Feeding policy).

G. To promote parent-infant bonding and family-centered care (refer to Family-Centered Care and Education policy)

H. Provide learning opportunities for parents that promote safe and developmentally appropriate feeding techniques (refer to Family-Centered Patient Care and Education policy; NICU Infant Care policy).

\section{DEFINITIONS}

A. Cue-Based Feeding: A safe, efficient, infant-centered, oral feeding program that emphasizes the individual infant's developmentally-driven oral feeding cues, commonly referred to as "infant-driven feeding" or "natural schedule of eating". The infant gives cues using physiological signals, as well as, motor and state systems (neurobehavioral maturation), to let caregivers know when to offer nonnutritive and nutritive oral feeding experiences.

B. Mon-nutritive breast feeding (NNBF): Allowing the infant to go to the breast to nuzde, root, and attempt latch, without requiring the baby to suck and express milk. This is particularly beneficial for infants that are not showing strong readiness for safe oral feeding (readiness scores of 3 or 4), but are showning the desire to orally feed. Providing NMBF during gavage feeding has been shown to facilitate the development of strong feeding cues, improve maternal-infant bond and breast feeding technique, as well as, improve maternal millk production.

C. Non-nutritive suck (NN5): Offering a pacifier to promote sucking and comfort. Often used as a pre-oral feeding activity, providing NNS during gavage feeding improves oral feeding mechanics and facilitates the development of feeding cues through increased association between sucking and receiving nutrition.

D. Oral Feeding Readiness Cues: Developmentally-driven feeding cues (signs) that alert caregivers that the infant is ready to actively eat by mouth. Examples cues coudd include:

1. Rooting

2. Hands to mouth, chewing on the hand

3. Ohh face

4. Lip smacking

5. Taking pacifier

6. Drowsy, alert, or fusssy prior to cares 


\section{Good body and muscle tone}

E. Stress or Mon-Readiness Cues: These are cues (signs) that the infant is not developmentally ready to eat by mouth or manifesting physiological instability making oral feeding unsafe. Examples of stress cues could include:

1. No presence of readiness cues.

2. Apnea/Bradycardia/Desaturation (As/Bs/Ds) during cares, or increased axygen requirements during cares (e.g. SaO2 less than or equal to $75 \%$ w/stimulation and slow recovery)(refer to Nicu Infant Care policy).

3. Tachypnea/Tachycardia 10-20\% above baseline during cares(refer to NICU Infant Care policy).

4. Fussiness/irritability that requires breaks or consoling measures in order to complete cares.

5. Sleeping throughout cares, no changes in tone.

\section{POLICY}

A. Once an infant has reached 32 weeks post-menstrual age (PMA), the RN will initiate the oral feeding readiness assessment [found in Electronic health Record (EHR), NICU Daily Cares/Safety Doc Flow Sheets].

B. An infant that has achieved at least 32 meeks PMA must also be physiologically stable and not receiving advanced respiratory/ventilator support via mechanical ventilator or continuous positive airway pressure (Bubble CPAP, SiPAP), or inotropes for cardiovascular/blood pressure support. Infants receiving these treatments (at any PMA) would not be appropriate, for oral feeding readiness evaluation (refer to NICU infant Care policy, Respiratory Policies).

C. Achievement of 32 weeks PMA does not mean that the infant will automatically start oral feedings: however, active assessment of the infant's oral feeding readiness will begin -

D. Once initiated, the oral feeding readiness assessment is ongoing and meant to be completed prior to each feeding: the oral feeding assessment is dynamic and designed to reflect/verify any changes in infant feeding readiness. The oral feeding readiness assessment should allow the RN to assess and document aral feeding progression or regression.

E. RN to initiate and update interdisciplinary care plan to include cue-based feeding readiness and progression to oral feeding achievement.

F. RN to notify provider when infant (initially) exhibits 2 consecutive oral feeding scores indicating readiness (for example a 1 or 2 on the readiness scale), to facilitate the provider's development of an aral feeding plan.

G. RN to collaborate with providers, keeping them updated with any changing oral feeding readiness scores, so that oral feeding progression can be modified as needed, to ensure that oral feeding is safe and developmentally supportive.

H. Each infant will be fed with a focus on its individual health, stability level, and developmental feeding readiness, as specified by providers (refer to NICU Infant Care policy).

1. RN to initiate and update parent education to include feeding readiness topics (refer to FamilyCentered Patient Care and Education policy).

J. Parent/family education and participation in infant care/feeding will be initiated as soon after admission as is reasonable and encouraged throughout the infant's hospital course (refer to NICU Infant Care policy).

K. Encourage active parent participation in recognition of infant"s feeding cues upon implementation of feeding readiness assessment and throughout the infant's hospital course.

\section{EQUIPMENT}

A. Type and arnount of formula or breast milk as available, and prescribed, in provider feeding orders.

B. Feeding tube that may be previously placed (refer to Gavage Feeding policy).

C. Bottle and selected nipple.

D. One-on-one verbal instruction/demonstration (parent education).

E. Pamphlets and written materials (parents and staff).

F. On-line materials (staff).

\section{PROCEDURE}




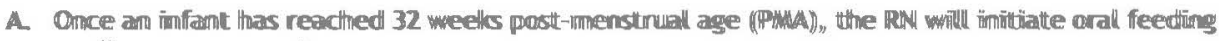
meadiness assersintents.

B. The oral feeding readiness assessment can be found in this policy, as well as, the NICU Daily Cares/Safety Doc Flow sheet (EPIC) and staff education.

C. As infants show readiness for safe oral feeding, RN will assess the quality of the oral feeding (breast or bottle) event, using either the Quality Bottle Feeding or Quality Breast Feeding Assessment Scales.

D. RM will also assess and document the caregiver techniques used during the feeding, as well as, any events that disrupted the feeding.

E. For infants that do not meet the criteria to begin oral feeding or feeding readiness evaluation (e.g. < 32 weeks PMA, physiologically unstable at any PMA, or as ordered by provider following their assessment), the RN would document: 1) gavage only (5) from the readiness assessment scale (readiness row found in EPIC charting) for those infants who are only feeding by gavage, or, 2) NPO status as ordered by providers. The rest of the oral feeding readiness assessment scales would not apply and would not be documented on,

F. The following $\mathbf{4}$ scales will be used for assessment of feeding readiness and quality:

1. Oral Feeding Readiness Assessment Scale

\begin{tabular}{|c|c|c|}
\hline Evaluation & Score & Description \\
\hline $\begin{array}{l}\text { Ready to Bottle or } \\
\text { Breast Feed }\end{array}$ & 1 & $\begin{array}{l}\text { Drowsy, alert or fussy prior to care. Rooting and/or hands to r } \\
\text { pacifier. Good tone. "Ohh face" }\end{array}$ \\
\hline $\begin{array}{l}\text { Ready to Bottle or } \\
\text { Breast Feed }\end{array}$ & 2 & $\begin{array}{l}\text { Drowsy or alert once handled. Some rooting or takes pacifier. } \\
\text { tone. }\end{array}$ \\
\hline $\begin{array}{l}\text { Limited } \\
\text { Bottle/Breast or NNBF }\end{array}$ & 3 & Briefty alert with care. No hunger behaviors. No change in ton \\
\hline $\begin{array}{l}\text { Limited Bottle/Breast } \\
\text { or MNBF }\end{array}$ & 4 & Steeping throughout care. No hunger cues. No change in tone. \\
\hline Gavage Only & 5 & $\begin{array}{l}\text { Needs increased } 02 \text { with care. } A / B \text { with care. Tachypnea over } \\
\text { care, }\end{array}$ \\
\hline
\end{tabular}

2. Quality Bottle Feeding Assessment Scale

\begin{tabular}{|c|c|c|}
\hline Evaluation & Score & Description \\
\hline Bottling Well & 1 & Nipples with a sturong coordinated suck throughout feed. \\
\hline Bottling Fair & 2 & $\begin{array}{l}\text { Nipples with a strong coordinated suck initially, but fatigues w } \\
\text { progression. }\end{array}$ \\
\hline Bottling Fair & 3 & $\begin{array}{l}\text { Nipples with consistent suck, but difficulty coordinating swalts } \\
\text { of liquid or difficulty pacing. Benefits from external pacing. }\end{array}$ \\
\hline Bottling Poor & 4 & $\begin{array}{l}\text { Nipples with a weak/ inconsistent suck. Littlie to no rhythm. Ma } \\
\text { some rest breaks. }\end{array}$ \\
\hline Unable to Bottle Safely & 5 & $\begin{array}{l}\text { Disorganized: Unable to coordinate suck/ swallow / breathe p } \\
\text { significant difficulty initiating suck. Does not benefit from pac } \\
\text { in frequent or significant A/B's or large amounts of tiquid loss } \\
\text { tachypnea significantly abowe baseline with feeding. }\end{array}$ \\
\hline Unable to Bottle Safely & 6 & Dysfunctional: Abnormal or deviant oral motor patterns. Unab \\
\hline
\end{tabular}




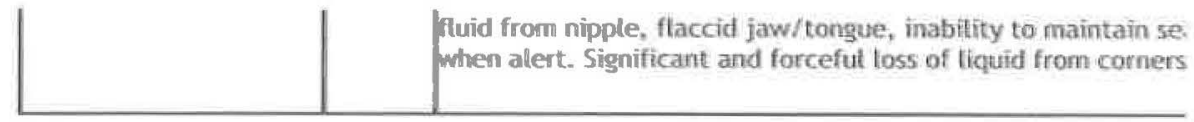

3. Quality Breast Feeding Assessment Scale

\begin{tabular}{|c|c|c|}
\hline Evaluation & Score & Description \\
\hline Breast Feeding Well & 1 & Latched well with a sturong coordinated suck for $>15 \mathrm{~min}$. \\
\hline Breast Feeding Fair & 2 & $\begin{array}{l}\text { Latched well with a strong coordinated suck initially, but fatic } \\
\text { progression. Active suck for } 8 \text {-min. }\end{array}$ \\
\hline Breast Feeding Fair & 3 & $\begin{array}{l}\text { Difficulty maintaining a strong, consistent latch. May be able } 1 \\
\text { intermittently nurse but only for }<8 \text { min. }\end{array}$ \\
\hline Breast Feeding Poor & 4 & 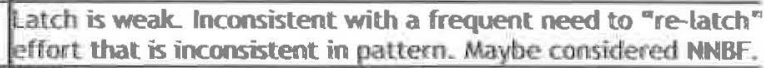 \\
\hline $\begin{array}{l}\text { Unable to Breast Feed } \\
\text { Safely }\end{array}$ & 5 & $\begin{array}{l}\text { Unable to latch to breast and achieve suck / swallow / breath } \\
\text { have difficulty arousing to state conductive to breastfeeding. } \\
\text { Frequent or significant A/B"s and/or tachypnea significantly al } \\
\text { with feeding. }\end{array}$ \\
\hline
\end{tabular}

4. Caregiver Techniques

\begin{tabular}{|l|l}
\hline Type & Description \\
\hline A & Side-Lying Position \\
\hline B & External Pacing \\
\hline C & Adding or lncreasing 02 during feed \\
\hline D & Imposed Breals \\
\hline E & Stimulation for recovery from As/Bs/Ds \\
\hline F & Frequent Burping \\
\hline H & Nipple change during feeding \\
\hline
\end{tabular}

Increased number of caregiver techniques selected indicates less readiness to orally feed, and/or feeding that could be unsafe.

G. Guidelines for Breat Feeding Supplementation:

1. For breast feeding infants, unless otherwise directed by provider orders, the following feeding length guidelines in conjunction with the assessed quality of the breast feeding event, are recommended for breast feeding supplementation.

a. If infant breastfed $<8$ minutes: bottle or gavage the entire feeding volume

b. If the infant breastfed 8-15 minutes: bottle or gavage half of the feeding volume

c. If the infant breastfed > 15 minutes: no supplementation with bottle or gavage unless the infaint acts hungry.

H. Guidelines for Feeding Tube Removal or Replacement:

1. As infants acquire oral feeding competence, unless otherwise directed by provider orders, the following guidelines are recommended for the removal or retum of feeding tubes: 


\section{IMPACT OF CUE-BASED FEEDING PROTOCOL}

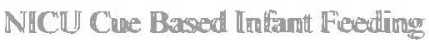

a. For any ünfant who is not able to complete oral feeding, rescue feed the remaining wolume through the feeding tube, as ordered by providers (cursent practice) (refer to Gavage Feeding policy).

b. Feeding tube removal recommended after $\mathbf{2 4}$ hours of successful breast/bottle feeding.

c. For infants that have had their tubes previously removed after successful oral feeding, the following is recommended for replacement of the feeding tube:

i. If at any point an infant cannot eat at least $50 \%$ of their ordered feeding, feeding tube replacement recommended, with an immediate update to providers with the feeding changes that necessitated return of feeding tube.

ii. If an infant eats between $\mathbf{5 0}$ and $\mathbf{1 0 0 \%}$ of their ordered feeding, allow this, but evaluate their next feeding volume and effort, for possible tube replacement.

\section{EDUCATION}

A. Staff education topics, delivered via on-line modules, include the following:

1. Developmental emergence of feeding cues

2. Cue-based feeding protocol

3. Cue-based feeding parent education

4. Cue-based feeding documentation

B. Complete Family Education plan in collaboration with parents (refer to Family-Centered Patient Care and Education policy).

C. Provide feeding instructions to parents that emphasize developmental readiness and safely (include important teaching points listed in power point) -

D. Examples of feeding education topics can indude:

1. Discuuss the presence of the infant's abilitty to suck and coordinate swallowing by $\mathbf{2 8}$ weeks postmenstrual age (PMA).

2. Discuss the infant's development of coordinated sudking and swallowing develops between 32 and 34 weeks PMA. Developmental cues showing a readiness to orally eat begin to emerge during this period as well.

3. Coordination of surking, swallowing and respiratory cycles typically matures between 34 and 36 weeks PMA. Feeding readiness cues become stronger, more consistent.

4. At 36 weeks PMA, infants may require supportive interventions to optimize coordination of sucking, swallowing, and breathing.

5. Explain transition from tube feeding to oral feeding.

6. Discuss what is meant by "cue-based feeding" and give examples of feeding readiness cues.

7. Discuss examples of stress or non-readiness cues and discuss what can delay the onset of feeding readiness cues.

8. Discuss the meaning of "quality feeding."

9. Discuss the importance of the parent-infant bond durring feeding and the necessity to focus on the infant's feeding ability.

10. Supportive interventions to optimize the coordination of sucking, swallowing, and breathing could include side-lying position, neutral chim position, chir and cheek support, pacing, imposed breaks, nipple selection, and locose swaddling.

11. Explain the different types of nipples used for bottle feeding and advantages/disadvantages for each for flow rate and sucking mechanics.

12. Discuss speech therapist consultation and any findings and recommendations from speech therapists.

13. For breast feeding mothers discuss assessment of breast feeding quality and length, and provide ordered/policy guidelines for supplementation of breast feeding as needed.

14. Explain rationale and benefits of non-nutritive breast feeding (NNBF) and non-mutritive suck (NNS).

15. Explain ordered/policy guidelines for feeding tube removal and/or replacement.

16. Discuss with parents that feeding cues can help them determine when baby is truly hungry or 


\section{IMPACT OF CUE-BASED FEEDING PROTOCOL}

NICU Cue Bassed Iraffarent Foeding

Pagise 6 of 7

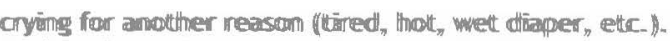

17. Explain thatt an decrease or absence of feediings cues may indicate that the baby is getting sick.

\section{DOCUMENTATION}

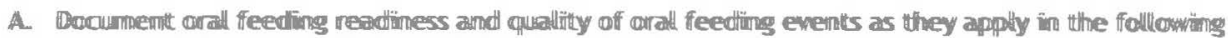
sectioms of the NiKCU Daily Cares/Safety Doc Flow Sheet in the Ellecturonic. Heatth Record (EHHR):

1. Feeding Readiness Assessment

2. Quality Bottle

3. Quality Breast

4. Caregiver Techniques

B. Document parent visits, information or instruction provided, and assessments of understanding and proficiency in providing oral feeding in:

1. Parent/Family Education Flow Sheet and Electronic Health Record (EHR) (refer to FamilyCentered Patient Care and Education policy).

\section{REFERENCES}

Armaizu, N., Shulman, R., Schanler, R., \& Lau,C. (2008). Maturation of oral feeding skills in preterm infants. Acta Paediatr. 97(1), $61-67$.

Anderson, G.C., Benhke, M., Gill, N., Conton, M., Measel, C.P., G McDonie, T.E. (1990). Self-regulatory gavage to bottle feeding for preterm infants: effect on behavioral state, energy expenditure, and weight gain. In Funk, S.G., Tomquist, E. M.,

Champagne, M.T., Coop, L.A., \& Wiese, R.A. (eds). Key Aspects of Recovery: Improving Nutrition, Rest and Mability. 83-97, New York, NY: Springer.

Arvedson, J., Clark, H., Lazanus, C., Schooling, T., \& Frymark, T. (2010). Evidence-based systematic review. Effects of oral motor interventions on feeding and swallowing in preterm infants. American Journal of Speech-Language Pathology, 19, 321-340.

Bakewell-Sachs, S., Medoff-Cooper, B., Escobar, G.J., Silber, J.H., \& Lorch, S. A. (2009). Infant functional status: the timing of physiologic maturation of premature infants. Pediatrics. 123(5), e878-e886.

Barlow, S.M. (2009). Oral and respiratory control for preterm feeding. Curr Opin Otolaryngol Head Neck Surg- 17(3), 179-186.

Browne, J.V., \& Ross, E. S. (2011). Eating as a neurodevelopmental process for high-risk newborns. Clinical Perinatology. 38(4), 731-743.

National Association of Neonatal Nurses (NANN) (2013). Infant-Directed Oral Feeding for Premature and Critically III Hospitalized Infants: Guideline for Practice. 1-15, Retrieved from: www.nann.org.

Newland, L., L'Huillier, M.W., Petrey, B. (2013). Implementation of cue-based feeding in a level III NICU. Neonatal Network, 32(2). 132-137.

Shaker, C.S. (1990). Nipple feeding premature infants: a different perspective. Neonatal Network, 8(5). 917.

Shaker, C.S. (2013). Cue-based feeding in the NICU: Using the infant's communication as a guide. Neonatal Network, 32(6). 404-408. 


\title{
IMPACT OF CUE-BASED FEEDING PROTOCOL
}

NICU Cue Based Infant Feeding

Page 7 of 7

Thoyre, S.M. (2007). Feeding outcomes of extremely premature infants after neonatal care. Nournal of Gynecological \& Neonatal Nursing, 36(4). 94-100.

\section{Referenced Documents}

\author{
Reference Type Title Notes \\ Docursents referenced by this document \\ Referenced Documents Family-Centered Patient Care and Education \\ Referenced Documents Gavage Feeding \\ Referenced Documents Developmentall Care \\ Referenced Documents Respiratory Policies \\ Referenced Documents NICU Infant Care \\ Paper copies of this document may not be current and should not be relied on for official purposes. The current \\ version is in Lucidoc at .

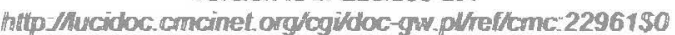

